NBER WORKING PAPER SERIES

\title{
SAVING BABIES: THE EFFICACY AND COST OF RECENT EXPANSIONS OF MEDICAID ELIGIBILITY FOR \\ PREGNANT WOMEN
}

\author{
Janet Currie \\ Jonathan Gruber
}

Working Paper No. 4644

\section{NATIONAL BUREAU OF ECONOMIC RESEARCH \\ 1050 Massachusetts Avenue \\ Cambridge, MA 02138 \\ February 1994}

\begin{abstract}
We are grateful to Peter Diamond, Sarah Feldman, Guido Imbens, Alan Krueger, Jim Poterba, Jon Skinner, Doug Staiger, Steve Stern, Duncan Thomas, Aaron Yelowitz, and to seminar participants at Comell, UVA, and the NBER for helpful discussions, to Sharieff Mansour and Nancy Cole for excellent research assistance, and to Marilyn Ellwood, Michael Fischer, Ian Hill, and Aaron Yelowitz for providing information on Medicaid policies. Janet Currie gratefully acknowledges support from the National Science Foundation (SES-9122640) and the Alfred P. Sloan Foundation. The views expressed are solely the authors' and should not be attributed to either organization, or to the National Bureau of Economic Research. This paper is part of NBER's research programs in Health Care and Health Economics.
\end{abstract}


NBER Working Paper \#4644

February 1994

\title{
SAVING BABIES: THE EFFICACY AND \\ COST OF RECENT EXPANSIONS OF \\ MEDICAID ELIGIBILITY FOR PREGNANT WOMEN
}

\begin{abstract}
A key question for health care reform in the U.S. is whether expanded health insurance eligibility will lead to improvements in health outcomes. We address this question in the context of dramatic expansions in the Medicaid eligibility for pregnant women that took place during the 1980s. We build a detailed simulation model of each state's Medicaid policy during the 19791990 period, and use this model to estimate 1) the effect of changes in the rules on the eligibility of pregnant women for Medicaid, and 2) the effect of Medicaid eligibility changes on birth outcomes in aggregate Vital Statistics data.

We have three main findings. First, the expansions did dramatically increase the Medicaid eligibility of pregnant women, but did so at quite differential rates across the states. Second, the expansions lowered the incidence of infant mortality and low birthweight; we estimate that the 20 percentage point increase in eligibility among 15-44 year old women was associated with a decrease in infant mortality of 7\%. Third, earlier, targeted changes in Medicaid eligibility, such as through relaxations of the family structure requirements from the AFDC program, had much larger effects on birth outcomes than broader expansions of eligibility to all women with somewhat higher income levels. We suggest that the source of this difference was the much lower takeup of Medicaid coverage by individuals who became eligible under the broader expansions. We find that the targeted expansions, which raisod Medicaid expenditures by $\$ 1.7$ million per infant life saved, were in line with conventional estimates of the value of a life. We conclude that insurance expansions can improve health, but that translating eligibility to coverage may be the key link in making insurance policy effective.
\end{abstract}

Janet Currie

Department of Economics

University of California, Los Angeles

405 Hilgard Avenue

Los Angeles, CA 90024

and NBER
Jonathan Gruber

National Bureau of Economic Research

1050 Massachusetts Avenue

Cambridge, MA 02138

and NBER 
Will the extension of health insurance to the uninsured improve their health? This is a key question underly ing the current debate over health care reform. Although insurance coverage may be a necessary precondition for improvements in the utilization of medical care, expansions in eligibility for insurance may not translate into increased utilization of care, or even into increases in insurance coverage. It is also possible that increased utilization of care will not result in improvernents in health.

This paper sheds light on these issues by investigating the relationship between the health of newborns and recent expansions of the insurance coverage provided to pregnant women under the Medicaid program. With 10 infant deaths per 1000 births, the U.S. infant mortality rate exceeds that of 20 other industrialized nations (U.S. House of Representatives, 1992). This high rate is thought to reflect large numbers of unhealthy newborns. Hence, to the extent that adequate prenatal care improves neonatal health, there is scope for a decrease in this rate through the promotion of prenatal care (Institute of Medicine, 1985).

In an effort 10 increase the use of prenatal care, the past decade has seen a rapid expansion in the eligibility of pregnant women for Medicaid, a federal-state matching entitlement program that provides health insurance for the poor. Eligibility for Medicaid had traditionally been tied to the receipt of cash welfare payments under the Aid for Families with Dependent Children (AFDC) program. This generally limited eligibility to very low income women in single parent households. However, eligibility was extended to a number of additional groups of pregnant women during the 1980s. This experience provides a case study of whether expanding health insurance eligibility can actually improve infant health, or whether poor infant health in the U.S. simply reflects other factors beyond the reach of government insurance policy.

To study the effect of this government intervention, we exploit the fact that the eligibility changes occurred at different rates across the states in order to Identify their effects on birth 
outcomes, birth inputs, Medicaid coverage, and Medicaid expenditures. The backbone of our analysis is a detailed simulation model of each state's Medicaid eligibility rules for pregnant women over the 1979-90 period. We apply this model to data from the Current Population Surveys (CPS) in order to quantify the effects of changes in the rules on eligibility and on actual Medicaid coverage. We then use aggregate Viral Startsitics data to examine the effect of the expansions on two widely used indicators of infant health: the incidence of low birthweight, and infant mortality. Using these estimates in conjunction with data on Medicaid expendiuures from the Health Care Financing Administration (HCFA), we then examine the costliness of Medicaid expansions. Finally, we use information on the use of medical services by pregnant women from the National Longitudinal Survey of Youth (NLSY) to ask how the policy changes affected the use of birth inputs.

We have three major fisdings. First, we estimate that the expansions of the 1980 s increased the fraction of women eligible for public insurance in the event of pregnancy from 14.2 to $34 \%$, an increase of $140 \%$. This increase occurred at quite different rates across the states, causing dramatic changes in relative state generosity. Second, increases in Medicaid eligibility were associated with a lower incidence of low birthweight birchs and a decrease in infant mortality: the effect on infant mortality was stronger than the effect on low birthweight. Third, all Medlcaid eligibility changes are not created equal. In particular, the changes can be divided into two categories. "Targeted expansions" were narrowly targeted changes which included changes in eligibility criteria for cash welfare under the AFDC program, and expansions of Medicaid eligibility to demographic groups who had been ineligible for AFDC for reasons of family structure. "Broad expansions" were extensions of Medicaid coverage to all women with incomes less than specified levels (e.g. 185\% of the federal poverty level). These two types of policy changes affected quite different populations, suggesting the potential for heterogeneity in their effects. 
In fact, we find that the targeted expansions had sizeable and significant effects on birth outcomes, while the broad expansions had litte effect. We suggest that the source of this difference is in the differential effects that these policies had on Medicaid coverage; the broader expansions featured much lower cakeup rates, even among otherwise uninsured mothers. The targeted expansions were associated with a Medicaid expenditure increase of $\mathbf{S 1 . 7}$ million per infant life saved. This figure is fairly low compared to recent estimates of the value of a life. However, it is high relative to clinical estimates of the costs of saving a life through improved prenatal care. We are unable to resolve whether this reflects a failure of prenatal care to deliver its promised savings, or a failure of mothers to obtain such care once they were eligible for Medicaid.

The rest of the paper is laid out as follows: In Part I, we provide background information about our measures of newborn health. In Part II, we discuss the Medicajd expansions, and their effects on eligibility. Part III investigates the effect of these expansions on birth outcomes. Part IV discusses the differential effects of the targeted and broad expansions on Medicaid coverage. Part $V$ investigates the cost-effectiveness of the targeted expansions using information on Medicaid expendiaures and individual use of prenatal care. Part VI concludes with a discussion of the policy implications of our findings.

\section{Background on Birth Outcomes in the U.S.}

The infant mortality rate and the incidence of low birthweight are two of the most frequently examined indicators of infant health. Figures $1 \mathrm{a}$ and $\mathrm{lb}$ plot the trends in these measures over the 19803. The incidence of low birtiwejght, defined as the number of live births per 1000 weighing less than 2500 grams (approximately 5.5 pounds), declined from 68.7 in 1979 to 66.6 in 1984, but then rose to 69.4 by 1990 . In contrast, infant mortality declined throughout the decade, although 
it declined af a slower rate between 1984 and 1989 than it had earlier. These differing trends underscore the fact that although they are related, low birthweight and infant mortality measure different aspects of birth outcomes.

Low birthweight is a key indicator of the underlying health of the fetus. Children who are of low birthweight are at high risk of neonatal mortality and experience post-neonatal mortality rates 10 to 15 times those found among normal birthweight infants (Office of Technology Assessment, 1987a). Horbar et al. (1993) found that in a sample of very low birthweight children weighing between 601 and $1300 \mathrm{grams}$ at birth, each increase in birthweight of 100 grams was associated with a decrease of approximately $10 \%$ in the probability of death, other things being equal.

In contrast, infant mortality rates reflect not only the health of the fetus as measured by birthweight, but also the effect of any interventions that occur during or shortly after birth. New technologies have had dramatic effects on the survival rate of low birthweight infants. Buehler et al. (1985) report that improvements in birthweight-specific mortality rates accounted for $91 \%$ of the overall decline in neonatal mortality between 1960 and $1980 . '$

These interventions, however, are often very expensive. Schwartz (1989) reports that although babies weighing less than 2500 grams account for only $9 \%$ of neonatal hospital caseloads. they account for $57 \%$ of the cost of neonatal hospital care. The average cost of caring for a surviving low birthweight baby was $\$ 9,712$ compared to $\$ 678$ for an infant weighing more than 2,500 grams. These costs rise as birthweight falls; in 1984, the cost of saving an infant with birthweight below 1000 grams was $\$ 118,000$ (OTA, 1987b). Moreover, survivors are at high risk

\footnotetext{
'More recently, Horbar es al. (1993) report that as much as half of the decline in national infant mortality reported between 1989 and 1990 may be attributable to the introduction of a new therapy for artificially replacing an essential substance in the lung (pulmonary surfactant) that is not masufactured by the fetus in significant quantities until the 33rd week. This therapy was introduced in October 1989.
} 
of handicaps such as cerebral palsy of signiflcant degree, major seizure disorders, blindness, deafness, and leaming disorders (McCormick et al., 1992; OTA, 1987b, Chaikind and Corman, 1990).

The high cost of caring for low birthweight infants and their uncertain future should they survive, have led policy makers to emphasize the prevention of low birthweight through the promotion of appropriate prenatal care. There are a number of ways that early prenatal care can improve fetal health. For example, approximately two-thirds of all low-birthweight births are preterm, and Creasy et al. (1980) found that over 60\% of these cases could have been identified using inexpensive (\$10 to \$20) screenings in the first prenatal care visit. Several clinical studies cited in the institute of Medicine's intluential 1985 report suggest that providing appropriate prenatal care to women identified by these screenings (at a cost of between $\$ 400$. and $\$ 500$. per woman) could reduce the incidence of low birthweight of more than $20 \%$. These figures imply that the cost of saving a life through improved prenatal care is at most $\$ 142,000$ per life saved. ${ }^{2}$

As has been noted by a number of economists, however, studies based on differences in outcomes among women who do and do not receive prenatal care are likely to be biased by selection; see Harris (1982) for an extensive discussion. Compared to clinical studies, studies based on survey data that attempt to control for this selection typically find much smaller effects of prenatal care on

\footnotetext{
2 This figure is calculated as follows. To screen 1000 pregnancies at a cost of $\$ 20$ each would cost $\$ 20,000$. One would expect 70 of these pregnancies to result in low birthweight births in the absence of any intervention. Of these, 47 will be pre-term, and $28(60 \%)$ will be caught by this screening. Prenatal care for these 28 women will then cost $\$ 14,000$, and will reduce the incidence of low birthweight by $20 \%$, or six babies. Using the Vital Startstics data below, we estimate that a decrease of one low birthweight baby per 1000 births lowers the infant mortality rate by 0.04 deaths per 1000 births. Thus, the $\$ 34,000$ spent to reduce low birthweight births by six babies will save 0.24 lives, for a cost of $\$ 141,667$ per life saved. This figure is an understatement of the benefits of prenatal care, since some of the babies who would not have died, but who are now of higher birthweight, will be less impaired later in life.
} 
birthweight (Rosenzweig and Schultr, 1982, 1983, 1988; Frank et al, 1991; Corman et al., 1987; Grossman and Joyce, 1990). These differences in results may also reflect the fact that clinical studies focus on the gains that could be atrained under ideal circumstances, whereas surveys reflect the impact of prenatal care as it is practiced in the field. For example, if prenatal care designed to reduce pre-term delivery were delivered not only to the women identified as high risk by screenings, but to all pregnant women, the cost of saving an infant life would rise to over $\$ 1.3$ million. ${ }^{3}$

In summary, the available clinical evidence suggests that while both reductions in the incidence of low birthweight and high-tech neonatal care can reduce infant mortality rates, the former is the more cost effective policy. Decreasing the incidence of low birthweight through increases in the use of prenatal care was in fact the primary motivation for the expansions in the Medicaid coverage of pregnant woman that took place during the 1980 s.

\section{The Medicaid Expansions}

\section{a) Background"}

Historically, Medicaid eligibility for women and children has been closely tied to participation in AFDC. This linkage with AFDC restricted access to the program in three ways. First, despite the existence of the AFDC-Unemployed Parents program which provides benefits to households in which the primary earner is unemployed, AFDC benefits are generally restricted to female-headed

\footnotetext{
${ }^{3}$ That is, there would be $\$ 500,000$ spent in delivering prenatal care to all 1000 women in the sample, and 9.4 pre-term low birthweight births would be prevented (since $100 \%$ of these cases would now be caught). This implies a cost per life saved of 1.33 million.

- The policies discussed in this section are those for which Federal matching funds were available. States can cover additional groups under Medicaid, but only if they pay the full cost of coverage. We do not have information about these "state-only" policies. In addition, we only discuss policies that applied to pregnant women. There were also expansions of the Medicaid coverage provided to children in this era; see Yelowitz (1993) for details.
} 
households.' Second, income cutoffs for cash welfare vary across states, and can be very low. For example, in Texas, the cutoff for a family of 4 in 1979 was oniy $24 \%$ of the poverty line. Third, the stigma of applying for cash welfare programs may have prevented eligible families from receiving Medicaid benefits (Moffit, 1992).

However, from the inception of the Medicaid program, states have had the option of extending Medicaid benefits to some groups of pregnant women who were not on AFDC. These options expanded rapidly during 1980s, in a manner that is detailed in the Appendix. In brief, these eligibility changes can be divided into two types. The first type expanded coverage to narrowly defined groups who had not traditionally qualified for AFDC. This included first time pregnant women and two parent families whose income was below AFDC cutoffs, and "Medically Needy" individuals whose income was somewhat above these cutofts but who had large medical expenses. Also included in this category are changes in AFDC income limits, which carry with them changes in Medicaid eligibility. Because these eligibility changes are narrowly targeted, we label them "targeted expansions".

Beginning in April 1987, the income requirements for Medicaid were also greatly liberalized. States were first given the option and then required to provide Medicaid coverage to women with income levels that greatly exceeded the AFDC income limits in most states. By April 1990, a uniform minimum threshold had been established - all states were required to cover pregnant women with incomes up to $133 \%$ of the poverty line, and states had the option of covering women with incomes up to $185 \%$ of the poverty line. In what follows, we will denote these relaxations of the income requirements as "broad expansions".

\footnotetext{
${ }^{5}$ Not every state had an AFDC-UP program over our sample period, and eligibility requirements are strict. As a result, as of 1990 only $5 \%$ of the AFDC caseload qualified under this program (U.S. House of Representatives, 1992).
} 


\section{b) Effects on Eligibilliry}

In order to estimate the effects of these eligibility expansions, we have built a detailed simulation of Medicaid policy in 49 states and the District of Columbia, over the 1979-j990 period. ${ }^{6}$ The construction of this simulation is described in detail in the Appendix. In this section, we use 12 years of CPS data to simulate the effect of the expansions on Medicaid eligibility. The CPS is the largest available annual data source with the requisite demographic and income information for undertaking this simulation.

Figure 2 a shows the fraction of 15 to 44 year old women in the CPS who would have been eligible for Medicaid coverage in each year had they become pregnant. The percent eligible rose from 14.2\% to $34 \%$ of this population between 1979 and 1990 . However, the eligibility increases of the early 803 show that these estimates are sensitive to business cycle effects. During the recession years, many women became eligible because they fell into poverty, so eligibility increased even as eligibility criteria became stricter in the early years of the Reagan administration.

In Figure 2b, the sample is restricted to women with incomes below twice the poverty line. The figure indicates that when business cycle effects are controlled for in this way, eligibility fell in 1982 as a result of cutbacks to the AFDC program in the early ' 80 s. Both figures show a moderate increase in eligibility associated with increases in the coverage of unborn children and twoearner families mandated in the Deficit Reduction Act of 1984 (DEFRA '84). But the figures clearly show that the most dramatic changes in the number of eligibles were associated with the relaxation

We exclude Arizona from the analysis because it does not have a conventional Medicaid progran. 
of income restrictions in the late 80s - eligibility increased almost 100\% between 1987 and $19900^{7}$

The aggregate time trends shown in Figures $2 \mathrm{a}$ and $2 \mathrm{~b}$ mask considerable variability in the growth of eligibility across states. Figures $3 \mathrm{a}$ and $3 \mathrm{~b}$ show two states with very different patterns: On the one hand, Ohio saw steady rises in eligibility from 1979 to 1988, and a relatively small jump between 1988 and 1990. On the other hand, Florida experienced little change in eligibility until 1988 , but large jumps in the last two years of the sample.

This variation is explored further in Table 1. Here, we show the fraction of 15-44 year old women eligible for Medicaid in each state, in each of the years 1979, 1986, and 1990. For 1990. we examine eligibility under the targeted and broad expansions separately, as well as overall eligibility. The growth from 1979 to 1986 under the targeted expansions is very dramatic in some states, such as Colorado, Minnesota, and Virginia, while there is litule growth in Delaware and even a reduction in states such as New Jersey. The growth from 1986 to 1990 is positive for all states, but there is also substantial variation; eligibility growth in Mississippi is over three times that of New Jersey."

it is this substantial change within states and over time that provides the identifying variation for our soudy. If states are ranked by the fraction of the $15-44$ year old female population that is eligible, the correlation between rank in 1990 and rank in 1979 is only 0.33 . Twenty-seven states experienced a change in ranking of at least 10 positions: Ulinois fell from the 8 th most generous state

\footnotetext{
'With in the set of targeted expansions, the policies that had the biggest effect were those that covered first-time pregnant women. The fact that these changes, and not the coverage of two-parent families, had the largest impact reflects the fact that few married couples were poor enough to qualify for the Medicaid program under the AFDC income cutoffs.

- Clearly, not all of the targeted eligibility changes were "expansions"; half of the states increased eligibility from 1986-1990, and half of them reduced it. On the other hand, almost every state shows a sizeable increase in eligibility under the broad expansions.
} 
to the 38th most generous, while Mississippi rose from the 44th most generous state to the state that makes the highest fraction of its population eligible.

\section{c) Targeted vs. Broad Expansions}

Throughout this paper, we will distinguish between the effects of the early and broad expansions. Our rationale for doing so is presented in Table 2, which highlights the heterogeneity of the populations affected by these two types of expansions. The first column shows the characteristics of the entire eligible sample. The second column examines the set of individuals covered under the targeted expansions, while the third looks at individuals who would not have been eligible under the targeted expansions, but were eligible under the broad expansions. All columns are based on data from the 1990 CPS.

While individuals covered by either the targeted or broad expansions appear disadvantaged relative to the full sample, the broad group appears to be more similar to the sample average than to the targeted group. Compared to the targeted group, the group covered by the broad expansions is somewhat wealthier, more likely to be white and married, and slightly older on average. Furthermore, the broad-expansion group is much more likely to be working, and less likely to be receiving any form of public assistance than the group covered by the targeted expansions; in fact, the group covered by the broad expansions is less likely to be receiving public assistance than the average 15-44 year old female. While the two groups are equally likely to be uninsured, the composition of insurance coverage differs substantially. Thirty-eight percent of the targetedexpansion group is covered by Medicaid, while only $13 \%$ of the broad-expansion group is; and only 7\% of the targeted group has employer-provided health insurance in their own name, while $25 \%$ of the broad group does. 
This population heterogeneity suggests that the two types of expansions may have had very different effects on birth outcomes. We will allow for such a differential effect in the estimation below.

\section{Eligibility and Birth Outcomes}

a) Methodology

We examine the effect of the eligibility expansions on birth outcomes using aggregate data from Visal Statistics, which reports the incidence of low birthweight (less than 2500 grams) and infant mortality in each state and year for the full sample of births in that state/year.' We match this data to two measures of eligibility among all $15-44$ year old women in each state and year over the 1979-1990 period. The first is the actual percentage of women made eligible under expansions; that is, we use the data presented in Table 1 for each of these years, matched to the birth outcomes data for that state/year.

A potential drawback to this strategy, however, is that the CPS traction-eligible measures may incorporate business cycle effects, or other shocks specific to states and years. Figure 2a showed, for example, that the recession of 1982 was associated with increases in Medicaid eligibility despite the adoption of stricter eligibility criteria. Similarly, the fact that in 1990 Mississippi had the highest fraction eligible of any state reflects both the generosity of the state program and the relative poverty of Mississippians.

To the extent that relevant state and year specific characteristics are not captured by state and

\footnotetext{
- in an earlier draft, we explored the effect of the expansions on low birthweight in the NLSY data discussed below. While the findings were supportive of our conclusions using aggregate data, the confidence intervals were too large to draw any useful conclusions. Furthermore, we were unable to investigate infant mortality with the NLSY due to small sample sizes.
} 
year dummies, (i.e. they are not constant within a state, or across states within a year), the coefficient on the fraction eligible will be biased by omitted variables. Suppose, for example, that a state recession is associated both with increases in eligibility and with a higher incidence of low birthweight. Then this source of variation in eligibility could induce a spurious positive correlation between Medicaid eligibility and low birthweight. 10

In order to overcome this problem, we have created a measure of "simulated eligibility". We first took a 1-in-10 sample of our CPS cohort of women for each year. We then calculated the fraction of this same sample of women who would have been eligible for Medicaid in each state in thas year. By using the same group of approximately 1000 women in each state simulation, we obtain an estimate of the fraction eligible that depends only on state rules, and is independent of other characteristics of states." Furthermore, we reduce the sampling variability in our estimate that derives from having relatively small cells for some states in the CPS.

These models treat state Medicaid policy as exogenous to birth outcomes; there is in fact some evidence which suggests that this assumption is not true. Gold et al. (1993) report that states with high proportions of low birthweight births and high fractions of women who delayed obtaining prenatal care were more likely to adopt optional expansions and to set up complementary advertising and outreach programs. In the models below, we will include state fixed effects which will control

\footnotetext{
${ }^{10} \mathrm{~A}$ similar bias could arise if adverse trends in birth outcomes are correlated with the absolute level of poverty, since expansions may have their largest impact where the population is poorest.

"We find for example that in Connecticut, actual eligibility for this cohort of women fell sharply in the mid-to-late-80s. Simulated ellgibility is much flatter, which indlcates that on average, young women in Connecticut fared better than those in other states. On the other hand, the increase in simulated eligibility is much flatter than the increase in actual eligibility in Mississippi, which indicates that women in Mississippi were poorer than a nationally representative group of women. Simulated eligibility will still vary with aggregate cyclical conditions, but this variation is absorbed in the year dummies included in the regression.
} 
for such spurious correlation between time invariant state characteristics and Medicaid policy.

\section{b) Overall Resulis}

Table 3 presents the basic regression results. All regressions include a full set of year effects, to control for the strong trends in infant mortality and low birthweight illustrated in Figures la and 1b. They also include a full set of state effects, to control for time invariant differences across states that may be correlated with both Medicaid policy and birth outcomes. Thus, the model is identified by the deviation of Medicaid eligibility from its state-specific mean.

The top panel of Table 3 models the overall effects of changes in Medicaid eligibility in the 1980s. When we use the actual fraction eligible, we find a negative effect on the incidence of low birthweight, but it is not statistically significare. The estimate rises when we use the simulated fraction eligible, and becomes significant at the $5 \%$ level. The coefficient suggests that a 20 percentage point increase in eligibility (roughly the magnitude of the expansions of the 1980s) would lead to a reduction of $2 \%$ in the rate of low birthweight. We conclude that there is some evidence of an effect of these expansions on the incidence of low birthweight, but the effect is relatively small.

On the other hand, there is a sizeable and significant effect of expanding Medicaid eligibility on infant mortality, regardless of the measure of eligibility used. The estimate from the simulated eligibility regression indicates that a 20 percentage point rise in eligibility under Medicaid led to a 7\% decline in the infant mortality rate. In the final two columns, we regress the incidence of infant mortality on the incidence of low birthweight and on our eligibility measure. The strong effect of eligibility on mortality is apparent even after conditioning on the positive correlation between eligibility changes and birthweight improvements.

Thus, there is evidence that eligibility for health insurance improves health, as measured by 
birth outcomes. in terms of their stated goal of reducing infant mortality, the expansions of the 1980 s were a success. ${ }^{12}$ We will explore the cost of this success below. First, however, we examine the heterogeneous effects of the different types of eligibility policies pursued over this period.

\section{c) Differential Effects of Targeted and Broad Expansions}

The bottom panel of Table 3 regresses the incidence of low birthweight and the infant mortality rate in each state and year on estimates of the percentage of women eligible for Medicaid under the targeted and broad expansions constructed from the CPS. The targeted regression is run over the full set of years (1979-1990), while the broad regression is nun over onily 1987-1990, the years that the broad expansions were in place. All the regressions include a full set of year and state dummies.

Table 3 shows that the targeted expansions have much stronger effects on both measures of infant health than the broad expansions. This result is strongest when we use the simulated fraction eligible, despite the fact that the estimates on percent eligible are equally precise across the two regressions. Using the simulated fraction eligible, we find that a 20 percentage point increase in eligibility was associated with a highly significant $4.5 \%$ decline in the incidence of low birthweight under the targeted expansions, but with oniy an insignificant $0.4 \%$ decline under the broad expansions. Similarly, a 20 percentage point eligibility rise was associated with a $7.3 \%$ decline in

120ur finding of stronger effects on infant mortality than on the incidence of low birthweight is consistent with that of Hanratty (1992), who examined the introduction of National Health Insurance in Canada, and found significant effects on mortality but mixed effects on birthweight. It does contrast with the finding of Fischer (1992), who also studied the effects of the Medicaid expansions from 1984 onwards. He found strong effects on the incidence of low birthweight for blacks, but no effects on mortality for either race. 
infant mortality under the targeted expansions, but with only a $0.6 \%$ decline under the broad expansions. The findings for infant mortality persist when we condition on the incidence of low birthweight. ${ }^{13}$

\section{Explaining the Heterogeneous Effects: The Role of Medicaid Takeup}

The birth outcome results presented above provide a mixed message. On the one hand, there is strong evidence that insurance eligibility can improve birth outcomes. On the other hand, the nature of the policy appears to be key. Why is it that the targeted expansions were so much more successful than the broad expansions in improving birth outcomes? We suggest thas the answer may lie in the differential takeup of these different types of eligibility changes by pregnant women.

As a number of researchers have emphasized, eligibility for social insurance and welfare programs does not automatically translate into coverage. For example, Blank and Ruggles find that only about two-thirds of women eligible for AFDC take up their benefits, and Blanik and Card (1991) find a similar takeup rate for unemployment insurance. Eligibility can not be expected to have an effect on fetal health unless individuals takeup their newly available Medicaid benefits.

The March CPS asks individuals if they were covered by Medicaid at any point in the

\footnotetext{
${ }^{13}$ We have aiso attempted finer divisions of the data. For example, we have tried separating the fraction eligible under the targeted expansions into those eligible under AFDC or the AFDCUnemployed Parent program, and those eligible under any other targeted expansion. We find that only the "other targeted expansions" had a statistically significant effect on the incidence of low birthweight. However the standard errors are large, and in the estimates using the simulated fractions eligible, we cannot reject the hypothesis that both types of targeted expansions had similar effects. For infant mortality we find using simulated eligibility that both types of targeted expansions had quite similar effects, although once again the standard etrors are large.
} 
previous year." We can therefore estimate the "Lakeup" elasticity of these expansions; that is, for every 100 women made eligible for coverage of pregnancy, how many additional women report coverage? Of women 15 to 44 years old, 6.5\% had a child in any given year during our sample period, so that about $11.5 \%$ of women in the relevant age range were pregnant at some point during the year. ${ }^{\text {Is }}$ By this calculation, a takeup rate of 0.115 in the entire population would represent full takeup by pregnant women. This figure is only a lower bound, however, since some of the Medicajd eligibility changes (those associated with the adoption of the AFDC-UP program, for example) covered not only pregnancy but also other conditions. Hence, the number of women who became pregnant is an undercount of those who became eligible for coverage under all eligibility changes.

We examine the relationship between Medicaid coverage and state/year average eligibility using linear probability models that control for other observable characteristics, including race, marital status, employment status, and income. Our data set consists of 455,774 observations over a 12 year period. All regressions include a full set of state and year dumnies. ${ }^{16}$

In the first column of Table 4, we include an indicator equal to 1 if a woman was eligible under either the targeted or the broad expansions. We find that there is an increase in the probability

14 Unfortunately, prior to March 1988, health insurance coverage in the CPS was assigned according to whether one received coverage under the policy beld by the head of the household. Thus, those dependents deriving coverage from outside the bousehold were counted as uninsured. After March 1988, each family member was asked about health insurance coverage from any source. This questionnaire change had its largest effect on children below the age of 15 , so that it should not significantly bias our results; furthermore, the inclusion of year dumnies will capture overall changes in the nature of responses.

is All women who give birth in a year, must have been pregnant at some time during that year. In addition, between $2 / 3$ and $3 / 4$ of women whose pregnancies begin in one year will give birth in the next year. Hence, the percent pregnant in any year is at least $(1+.67) * 6.5$, or $11.5 \%$.

${ }^{16}$ We use a linear probability model in order to facilitate the use of instrumental variables below, and for computational ease with our large sample size. 
of coverage of $2.4 \%$ for every $10 \%$ rise in eligibility. This estimate appears relatively high compared to the calculations given above. The other covariates have the expected effects; Medicaid coverage is less likely if individuals are white, married, working, or high income, and the probability of coverage increases with the number of children.

In the second and third columns, we disaggregate the eligibility measure into eligibility for a targeted expansion (over the 1979-1990 period) and eligibility for a broad expansion (over the 1987-1990 period). We find that the targeted expansions had much larger effects on coverage than the broad expansions; a $10 \%$ rise in the eligibility under the targeted expansions increased coverage by $2.7 \%$, while a $10 \%$ rise in eligibility under the broad expansions is actually estimated to decrease coverage.

Why did the targeted expansions have a bigger effect on coverage? One possibility is that the results are subject to omitted variables bias: there may be omitted characteristics that are correlated both with coverage and with eligibility. Suppose for example, that women whose mother's were on AFDC are both more likely to be eligible (because they are poor), and more likely to be covered (because they are familiar with the system). The bias associated with omitting the family's history of welfare dependency is likely to be more important in the case of the targeted expansions, because they applied to a lower income portion of the population.

In order to address this issue, we present instrumental variables estimates of the probability of Medicajd coverage in columns (4) through (7) of Table 4. The instrument is the fraction eligible in each state and year; in columns (4) and (5) we use the actual value, and in columns (6) and (7) we use the simulated measure. ${ }^{17}$ In both cases, the targeted expansions have much larger effects

\footnotetext{
"Using actual eligibility in each state and year is similar to instrumenting using the full set of state "year dumuies (it is equally consistent but less efficient), but is much less computationally burdensome. Actual eligibility remains potentially problematic in this context, since state/year
} 
than the broad expansions; in neither case is the coefficient for the broad expansions significant. When we use our preferred simulated instruments, we estimate that coverage increased by roughly 1\% for every $10 \%$ rise in targeted eligibility. This elasticity appears more reasonable in light of the calculations discussed above, and suggests that takeup was fairly high among the population eligible for the targeted expansions, but low among the population eligible for the broad expansions."

We can think of two other possible explanations for lower takeup rates under the broad expansions. First, the population eligible for the broad expansions was less needy; as Table 2 shows, this group had higher incomes and better access to employer provided health insurance. Second, given a level of need, the broader expansions may have been less effective. It may be difficult to bring women who have never received any sort of social assistance isto the Medicaid program, either because they do not know about it or because of stigma effects. Rymer and Adler (1987) report that many low-income families and their physicians are unaware that they can qualify for Medicaid even if they do not receive AFDC benefits. It may have been easier for program administrators to find and notify women eligible for the targeted expansions because these women had more frequent interactions with the government assistance system, as illustrated in Table 2. These two explanations clearly have differing welfare implications; the first suggests that the difference in takeup rates was fairly benign since the women who did not take up coverage were less likely to need it; the second suggests that women who needed the program were not aware of it.

recessions will increase both Medicaid eligibility and coverage.

"As discussed above, the targeted expansions are at least partially comprised of AFDC eligibility changes, which should have more lasting effects on coverage than pregnancy only expansions, while the broad expansions consist of pregnancy coverage only. It seems unlikely that this factor can explain a difference in coefficients of the magniude of those in Table 4; the majority of the total growth in eligibility under the targeted expansions was accounted for by changes in pregnancy-only coverage. 
In an effort to differentiate between these two hypotheses, we reran the instrumental variables models using the subsample of women without sources of health insurance coverage other than Medicaid. We present the results using the simulated instrument; the relative findings using the actual instrument are similar. The results are shown in the final two columns of Table 4. The estimates are similar to those for the full sample, and show that even among otherwise uninsured women, the targeted expansions had significant effects on coverage while the broad expansions did not. This suggests, therefore, that the broad expansions of eligibility failed to affect birth outcomes because they were not effectively translated into increases in coverage, even among needy women.

\section{Exploring the Cost-Effectiveness of the Expansions}

\section{a) Medicaid Payments per Infant Saved}

While the Medicaid expansions of the 1980s appear to have been successful in improving birch outcomes, this improvement cane at a cost to the Medicaid program. In this section, we use data on Medicaid expenditures to assess the cost effectiveness of the expansions.

States report their payments made under the Medicaid program to the Health Care Financing Administration each year. ${ }^{19}$ These reports break down expendiures according to the class of provider, and the category of recipient. We examine total expenditures on physicians, clinics, and inpatient and outpatient hospital costs for all non-disabled children and non-disabled/non-elderly adults. Unfortunately, these data are not available by type of service (ie. childbirth) or by detailed population type (ie. pregnant women and infants). We normalize the expenditures using the state's 15-44 year old female population in that year. All figures are in 1986 dollars; we deflate

\footnotetext{
${ }^{19}$ We are grateful to Killard Adamache of Health Services Research, Inc. for providing us with these data.
} 
expenditures on hospital inpatient and outpatient expendiures by the Consumer Price Index for hospital services, and expendiures for physician and clinic services by the CPI for physician's services. Once again, we regress this measure of expendiures on the actual and simulated measures of Medicajd eligibility, and disaggregate by the type of expansion (targeted versus broad).

The results are reported in Table S. As would be expected, the expansions significantly increased Medicaid expendinures; regressions using the simulated eligibility measure indicate that an additional eligible woman was associated with an increase in expenditures of $\$ 232$ per year. Expendiures on the targeted expansions were much larger, amounting to $\$ 449$ per eligible woman. In contrast, although the coefficient on eligibility under the broad expansions is sizeable, it is not statistically significant.

These data can be used to provide a rough estimate of the cost-effectiveness of the targeted Medicaid expansions. Using the simulated measure, we estimate that Medicaid spending increased by $\$ 449$ per woman who became eligible under the targeted expansions. We also find that a one percentage point rise in (simulated) targeted eligibility decreases the incidence of infant mortality by 0.04 deaths per 1000 births. Taken together, these findings imply that the cost of saving a life through the targeted expansions was $\$ 1.73$ million. 20

What does this imply for the efficiency of Medicaid policy? This figure appears high

\footnotetext{
20This figure is calculated as follows. To generate 1000 births, given the average fertility rate of 0.065 in our sample, would require 15,385 mothers. A one percentage point increase in eligibility in this sample would therefore cost $\$ 69,079$ (\$449 for each of 153.85 women). This would reduce the number of infant deaths by 0.04 . So, to reduce the number of infant deaths by one would cost $\$ 1.73$ million. Note that to the extent that the newly eligible women (under either type of expansion) were getting treated for free when they were uninsured, the net cost to society of the Medicaid expansions is lower than the costs to the Medicaid program. Saywell et al. (1989) show that the average cost of uncompensated care for pregnancy and childbirth in 1986 in Indiana was $\$ 2668$. Subtracting this from the cost per birth of the targeted expansions lowers the cost to society per life saved to $\$ 1.66$ million.
} 
compared to the cost of saving 2 low birthweight infant through technological intervention; as discussed above, the Office of Technological Assessment found that the average cost of saving an infant with birthweight less than $1000 \mathrm{grams}$ was $\$ 135,000 .^{21}$ However, this figure understates the effective cost of high-tech interventions, for two reasons. First, over $30 \%$ of these infants died, and we only have information on expenditures per infant that lived. In comparing the OTA flgure to ours, the cost per lived saved should be inflaced to account for babies that used resources, but were not saved. Second, we have no information on the quality of life of infants who are kept alive. As described in Part I, there is a distinct possibility that surviving low birthweight infants will suffer serious handicaps. Hence, to the extent that the Medicaid expansions were effective in reducing infant mortality through improvements in fetal health, their costs (per life of a given level of health) will be overstated relative to high-tech interventions.

Moreover, $\$ 1.73$ million is at the low end of the recent range of estimates for the value of a life. Manning et al. (1989) use data from studies of willingness to pay for a small change in the probability of survival to estimate that the value of a life is $\$ 1.66$ million. Cropper and Oates (1992) report that studies based on compensating differentials for risk of death on the job yield a value of life of between $\$ 1.6$ and $\$ 9.0$ million; Viscusi (1992) presents a broader range, with a preferred estimate of $\$ 12.1$ million. ${ }^{2}$ Judged by this yardstick, the targeted Medicaid expansions appear to have spent, at most, as much to keep an infant alive as that person would have been willing to pay

\footnotetext{
${ }^{21}$ This and all subsequent figures are expressed in 1986 dollars. Where deflation is necessary, it is done using the Medical care component of the CPI, for comparison to our expendibure figures. The correct deflator for this exercise is not obvious, but using different deflators would not substantially alter our conclusions.

2 Furthermore, compensating wage differentials understate the amount than an average person would pay to reduce the risk of death, because the least risk-averse persons tend to take the riskiest jobs.
} 
to be kept alive.

Alternatively, we can compare the cost of saving a life through the Medicaid expansions to the cost of keeping individuals alive through other public policy interventions. Graham and Vaupel (1980) report the cost of saving a life-year through 57 different public policy interventions, ranging from mandatory seat belts or air bags to reduced emissions. Using a life expectancy of 74.8 years (the U.S. average for 1986), 38 of their 57 interventions cost less than $\$ 1.7$ million per life saved. However, the other 19 interventions cost much more, and in some cases, the costs were as high as $\$ 30$ million. ${ }^{24}$ Cropper et al. (1992) estimate that regulations on the use of pesticides cost $\$ 60,000$ per consumer life saved, but that regulations on the production of pesticides cost $\$ 35$ million per producer life saved. Thus, while the targeted Medicaid expansions were not the most cost effective government life-saving intervention, they were much more efficient than some of the policies currently being pursued.

\section{b) Evidence from Individual-Level Dasa}

The results above suggest that the targeted Medicaid expansions may have been a cost effective means of saving infant lives. Nevertheless, the cost of doing so appears to be quite high relative to the promised cost savings from prenatal care discussed in Part I. There are two possible explanations for this high cost estimate. The first is that women failed to make use of cost-effective

\footnotetext{
${ }^{2}$ Relative to these other studies, our findings are subject to at least two (offsetting) biases. First, our estimates are likely to be too low, since we are valuing saving a life at birth, whereas the other studies are valuing saving the lives of workers or survey respondents. Second, our estimates may be too high, since the infants kept alive by medical interventions may be of worse health later in life, as described above.

${ }^{24}$ Furthermore, their calculations do not consider the cost of the intervention to the consumer; mandatory air bags have no cost to the government, but do increase the societal cost of saving a life.
} 
prenatal care when they were covered by Medicaid; that is, the infant lives that were saved may have come primarily through expensive hospital interventions. ${ }^{25}$ The second is that, in practice, prenatal care is not as cost effective as clinical sudies suggest, perhaps because it is not appropriately targeted. These alternative views obviously have very different implication for future policy design. Evidence from case studies of Medicaid expansions suggest that the former is the explanation for the high cost of saving an infant life. For example, Piper et al. (1990) found that a 1985 expansion of eligibility in Tennessee to married women increased Medicaid enrollments, but that most of the increase took place within the thirty days prior to delivery. Enrollment at such a late date would not allow for the effective use of prenatal care.

In this section, we attempt to distinguish between these views by examining the effect of the expansions on the use of prenatal care. ${ }^{26}$ We do so using individual-level data from the National Longitudinal Survey of Youth (NLSY) to examine the effects of eligibility under the targeted expansions on two indices of prenatal care use. The first is an indicator equal to one if the woman saw a doctor during the first trimester of pregnancy. Early initiation of prenatal care is important

\footnotetext{
${ }^{2}$ Women may have failed to take advantage of prenatal care because they were unaware of Medicaid eligibility, or because available providers were unwilling to accept Medicaid coverage. Neither of these problems would deter the use of expensive hospital care because hospitals that participate in Medicare are prohibited from refusing to treat, or from transferring, any women already in labor (OTA, 1987b). Furthermore, childbirth is the largest single component of hospital uncompensated care, accounting for 17.4\% of these expendiaures (Saywell et al., 1989). As a result, hospitals make every effort to enroll eligible uninsured women in Medicaid for the costs of childbirch (Gold et ah, 1993). Once enrolled, women may receive much more expensive services than their uninsured counterparts; Hadley et ol. (1991) and Wenneker et ol. (1990) find that uninsured patienis receive less intensive hospital treatment than insured patients along a number of margins.

${ }^{20}$ The expendiaure data do not offer much insight into this question. Both physician and hospital expendiaures rose significantly under the targeted expansions. It is difficult to draw further inferences from the relative changes in these categories, since the distinction between them is not clear; for instance, the physician category will include the costs of deliveries done by outside doctors, but perhaps not the costs of deliveries done by resident interns.
} 
both for conducting initial screenings, and for establishing a base-line for the monitoring of fetal development (OTA, 1987b). The second measure is an indicator equal to one if the woman had a sonogram during the first six months of the pregnancy. While there is no evidence that the use of ultrasound itself has any effect on the ferus, we view the receipt of an ultrasound before the point of delivery as a sign that a physician is monitoring the pregnancy.

The NLSY began in 1979 with a sample of 6,283 women between the ages of 14 and 21 . Since 1983, women have been asked bi-annual questions about the prenatal care that preceded each birth, including when they initiated prenatal care and questions about sonogram use. Retrospective information has also been collected for births before 1983. The NLSY also contains enough information about income, family structure, and state of residence to allow us to determine whether the woman was eligible for Medicajd coverage in the first trimester of the pregnancy. We do so using the same simulation program we applied to the CPS data.

After the exclusion of missing values, we are left with $\mathbf{4 7 5 9}$ observations on births that occurred between 1979 and $1990 .{ }^{27}$ It is important to note that the NLSY is not a representative sample of U.S. mothers in the relevant age range because African-Americans, Hispanics, and the poor were over-sampled. Almost half of the infants are African-American or Hispanic, and 73\% of the African-American infants, $78 \%$ of the Hispanic infants, and $32 \%$ of the other infants were born to mothers from the supplernental "poverty" sample.

The data indicate that throughout most of our sample period, women eligible for Medicaid coverage of their pregnancies are poorer, less educated, and more likely to be African-American or Hispanic relative to the sample as a whole, and even relative to the subsample of women with

${ }^{n}$ One shortcoming of these data is that the last available survey that asked about prenatal care and birth outcomes took place in the spring of 1990 . Information about births in the rest of 1990 must await the release of the 1992 survey. 
incomes below the poverty line. ${ }^{20}$ They also have much lower scores on the Armed Forces Qualification Test (AFQT), a standardized test of ability. ${ }^{29}$ Hence, it is not surprising that Medicaid-eligible women are $32 \%$ more likely to delay obtaining prenatal care: $27 \%$ of Medicaideligible women delay care compared to $20 \%$ in the entire sample. Similarly, $43 \%$ of Medicaideligible received a sonogram in the first 6 months compared to $48 \%$ of non-eligible women.

These comparisons highlight the possibility that estimates of the effects of individual Medicaid eligibility on the usage of prenatal care may be biased towards zero by omitted variables correlated with both eligibility and propensity to seek care. In order to address this problem, we instrument individual eligibility using first both the actual and the simulated fraction eligible measures from the CPS, calculated for this cohort of young women. ${ }^{30}$ We examine only the impact of the targeted expansions because the post-1987 sample size is quite small: Also, since only the targeted expansions affected Medicaid coverage, it seems reasonable to assume that the broad expansions had

21 In order to attenuate the effects of random measurement error and minimize the amount of missing data, we use the average income in the two years preceding the birth as our measure of income. If the woman was living with her parents then we use the parents' income less the need standard for a family of that size (following the procedure use by the AFDC program to impute family resources to minors living at home). Otherwise, we use the sum of the woman's own income, the spouse or partner's income, and "other" income. The use of this measure also avoids the imputation of eligibility for prenatal care on the basis of temporary income losses suffered after the birth.

29 Since the AFQT was administered to all the women at the same point in time, scores were normalized using the mother's age. Some readers may prefer to regard the AFQT as a summary measure of background and education, rather than as a measure of native ability.

${ }^{30}$ The problem that individual ellgibility may be correlated with unobserved determinants of outcomes has been noted in the wider social insurance literature. For example, unemployment insurance benefits are a function of lagged wages, and this may confound interpretation of the effect of those benefits on unemployment durations (Meyer, 1989). In that context, it may be easiest to control for the wage, or nonlinear functions of the wage, directly. Since Medicaid eligibility is a complicated function of a large number of individual characteristics, we prefer the instrumental variables strategy. 
little impact on the use of prenatal care.

We estimate logits models which include exogenous characteristics of the mother and child, in addition to a full set of year dummies." We also estimate models with and without a set of state dummies. As discussed above, the inclusion of state fixed effects controls for time invariant characteristics of states that may be correlated with state Medicaid policy. However, models with state fixed effects demand a lot of our data - although there are over 600 observations for the largest state (California), 9 states represented in our sample have fewer than 15 observations. We do not include fixed effects for these 9 states, so together they form the omitted "state".

The instrumental variables results are presented in Table 6. In the models without state effects, we find some evidence that the targeted expansions led to increased use of early prenatal care. Using the simulated instrument, our estimates imply that eligibility for Medicaid under the targeted expansions decreased the probability that the initiation of prenatal care was delayed beyond the first trimester by $13 \%$. There is no statistically significant effect on the use of sonograms in the first six months; the coefficient is wrong-signed. Once state effects are included in the model, none of the results are significant, although the sonogram result for the simulated instrument becomes right-signed (eligibility raises the probability of a sonogram in the first six months). However, the state effects themselves are not jointly statistically significant. Thus, the evidence on whether the targeted expansions were successful in increasing early contacts with physicians is mixed. These data are unable to definitively resolve whether prenatal care did or did not rise under the targeted expansions.

\section{Discussion and Conclusions}

\footnotetext{
"We use the predicted value of eligibility from the first stage linear probability model (individual eligibility regressed on state/year eligibility) directly in the second stage logit. This procedure is consistent but not efficient, and our standard errors are somewhat under-stated as a result.
} 
A key question for health reform is whether covering the uninsured will actually lead to improvements in health. While a number of studies have shown that the uninsured are in worse health, they are generally unable to surmount the problem that the uninsured may be fundamentally less healthy, independent of insurance stanus. ${ }^{32}$ Our approach to this problem is to examine exogenous changes in the Medicaid eligibility of pregnant women in the 1980 s. Judged by the most frequently used indicator of birth outcomes, the Medicaid expansions were a great success; infant mortality was reduced by $7 \%$ for every 20 percentage point rise in the fraction of 15 to 44 year old women eligible for Medicaid. Moreover, the cost of the policy seems to have been reasonable, relative to the value of a life or the cost of other government policies designed to save lives.

However, a closer look at the effects of the Medicaid expansions suggests that their success was limited, along two dimensions. First, the later broad expansions of Medicaid eligibility to all low income women appear to have had litule effect, primarily because they were not effectively translated into increased Medicaid coverage, even among needy (otherwise uninsured) women.

Second, the cost of saving a life under the targeted expansions was much higher than that suggested by clinical studies of prenatal care. We were unable to resolve whether this was due to the failure of women to obtain such care, or whether prenatal care is simply not as cost effective as clinical studies suggest. A fruitful direction for future research would be to investigate more carefully, perhaps through additional case studies of targeted expansions, the utilization of different types of prenatal and hospital care in response to the increased availability of public insurance.

Thus, our research offers two insights for the design of insurance policy. First, increased insurance eligibility can improve health outcomes, and the cost of doing so appears to be lower than

\footnotetext{
${ }^{32}$ One study which does surmount this problem is that of Lurie et al. (1984), which finds that individuals (exogenously) terminated from Medicaid due to California budget cutbacks saw reductions in their self-reported health.
} 


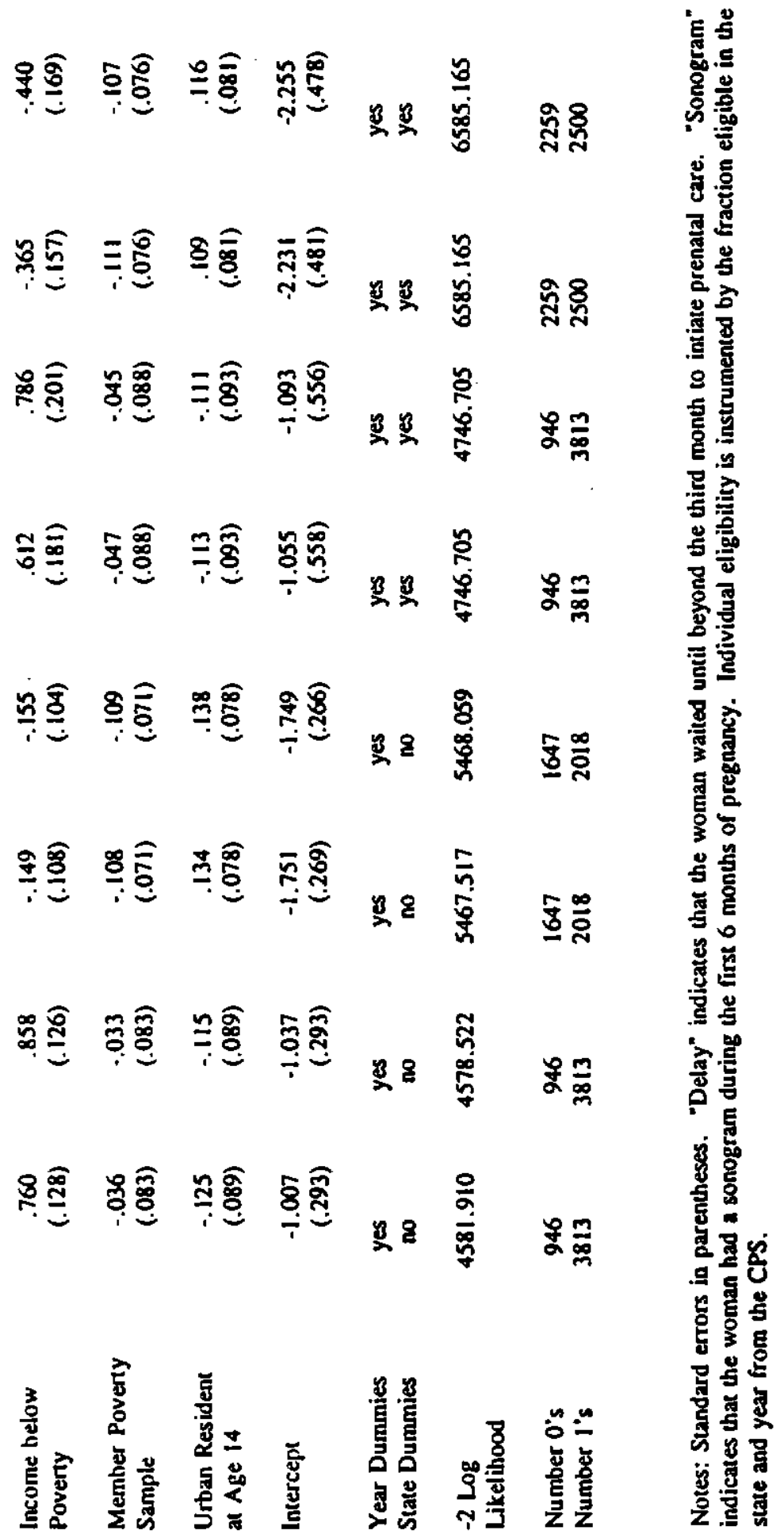


Table 1: Eligibility by State over Time

\begin{tabular}{llllll} 
ST & 1979 & 1986 & & \multicolumn{1}{c}{1990} & \\
& Any Exp. & Any Exp. & Any Exp. & Targeted & Brasd \\
AL & .146 & .214 & .342 & .148 & .194 \\
AK & .058 & .187 & .243 & .216 & .026 \\
AR & .123 & .151 & .307 & .137 & .169 \\
CA & .189 & .252 & .423 & .271 & .151 \\
CO & .095 & .192 & .236 & 107 & .128 \\
CT & .154 & .165 & .253 & .161 & .091 \\
DE & .114 & .114 & .243 & .092 & .150 \\
DC & .286 & .215 & .454 & .308 & .145 \\
FL & .094 & .133 & .361 & .170 & .190 \\
GA & .090 & .178 & .280 & .200 & .079 \\
HI & .202 & .179 & .389 & .222 & .167 \\
ID & .095 & .168 & .300 & .159 & .141 \\
IL & .171 & .186 & .268 & .181 & .086 \\
IN & .081 & .137 & .300 & .140 & .159 \\
IA & .103 & .165 & .380 & .136 & .243 \\
XS & .117 & .157 & .293 & .131 & .161 \\
XY & .119 & .154 & .396 & .210 & .186 \\
LA & .164 & .225 & .391 & .226 & .164 \\
ME & .141 & .200 & .420 & .222 & .198 \\
MD & .137 & .167 & .350 & .156 & .194 \\
MA & .156 & .165 & .352 & .209 & .142 \\
MI & .173 & .225 & .390 & .228 & .161 \\
MN & .099 & .209 & .375 & .184 & .191 \\
MS & .111 & .233 & .567 & .233 & .334 \\
MO & .092 & .155 & .273 & .109 & .164 \\
MT & .165 & .137 & .334 & .177 & .157 \\
NE & .133 & .153 & .233 & .114 & .118 \\
NV & .095 & .088 & .254 & .123 & .131 \\
NH & .096 & .072 & .184 & .128 & .055 \\
\hline
\end{tabular}




\begin{tabular}{|c|c|c|c|c|c|}
\hline \multirow[t]{2}{*}{$\mathbf{S T}$} & \multirow{2}{*}{$\begin{array}{l}1979 \\
\text { Any Exp. }\end{array}$} & \multicolumn{2}{|l|}{1986} & \multicolumn{2}{|c|}{1990} \\
\hline & & Any Exp. & Any Exp. & Targeted & Brond \\
\hline NJ & .157 & .149 & .232 & .157 & .074 \\
\hline $\mathbf{N M}$ & .110 & .147 & .347 & .137 & .210 \\
\hline NY & .238 & .242 & .411 & .257 & .153 \\
\hline NC & .106 & .150 & .364 & .202 & .162 \\
\hline ND & .110 & .134 & .279 & .146 & .133 \\
\hline $\mathrm{OH}$ & .131 & .187 & .278 & .172 & .105 \\
\hline OK & .139 & .162 & .314 & .198 & .116 \\
\hline OR & .161 & .155 & .264 & .145 & .119 \\
\hline PA & .138 & .164 & .293 & .182 & .111 \\
\hline $\mathbf{R I}$ & .197 & .152 & .352 & .187 & .164 \\
\hline SC & .150 & .228 & .401 & .160 & .241 \\
\hline SD & .110 & .149 & .277 & .131 & .146 \\
\hline$\pi N$ & .104 & .162 & .361 & .216 & .145 \\
\hline$T X$ & .079 & .143 & .318 & .141 & .176 \\
\hline UT & .132 & .255 & .243 & .140 & .102 \\
\hline VT & .228 & .234 & .396 & .239 & .157 \\
\hline VA & .129 & .245 & .271 & .136 & .135 \\
\hline WA & .170 & .242 & .262 & .165 & .097 \\
\hline$w V$ & .105 & .215 & .408 & .206 & .201 \\
\hline$w$ & .126 & .232 & .271 & .175 & .096 \\
\hline$W Y$ & .068 & .140 & .245 & .127 & .118 \\
\hline
\end{tabular}

Noter: Figures aro fraction of 15-44 year old wowen in each state/year eligible for Medicaid under iny expansion (column 1,2, and 3), targeted expansions only (column 4), and broad expansions conly (column 5). Tabulated from Merch 1980, 1987, and 1991 CPS. 
Table 2: Characteristics of the Population Covered Under

"Targeted" and "Broad" Expanslons, CPS Data

Characteristic

Full Sample

38,403

$(29,768)$

$24.9 \%$

Poor

Number of Kids

White

Age

Married

Working

Received Public

Assistance

Uninsured

Employer-Provided HI

Medicaid
1.26

(1.26)

$839 . \%$

29.9

(8.35)

$51.8 \%$

$74.7 \%$

$6.1 \%$

$16.4 \%$

$33.2 \%$

$10.1 \%$
Targeted
Expansions

18,775

$(27,676)$

$99.1 \%$

1.34

(1.41)

$71.7 \%$

25.8

(7.54)

$12.7 \%$

$52.6 \%$

$26.2 \%$

$30.1 \%$

$6.91 \%$

$37.6 \%$
Broad

Expansions

22,164

$(22,232)$

$38.5 \%$

1.31

(1.39)

$80.9 \%$

28.4

(7.67)

$38.0 \%$

$72.4 \%$

$5.08 \%$

$31.7 \%$

$25.4 \%$

$12.8 \%$

Notes: Data from 1990 sample of CPS. Working is defined as working at least one week in previous year; poor is family income below poverty line for that family size. 
Table 3: OLS Regressions of Low Birthweight and Infant Mortality on Eligibility Using Vhat Statistics Data for Each State and Year

Low Birthweight

Actual Simul. Elig.
Elis
Infant Mortelity

Actual Simul. Actual Simul

Models Using Fraction Eligible Under Any Expansion

\begin{tabular}{|c|c|c|c|c|c|c|}
\hline $\begin{array}{l}\text { Fraction } \\
\text { Eligible }\end{array}$ & $\begin{array}{c}-4.211 \\
(2.886)\end{array}$ & $\begin{array}{c}-7.431 \\
(3.848)\end{array}$ & $\begin{array}{l}-2.093 \\
(0.819)\end{array}$ & $\begin{array}{l}-3.458 \\
(1.090)\end{array}$ & $\begin{array}{l}-1.926 \\
(0.813)\end{array}$ & $\begin{array}{l}-3.171 \\
(1.085)\end{array}$ \\
\hline Low Birtbweight & & & & & $\begin{array}{c}0.040 \\
(0.012)\end{array}$ & $\begin{array}{c}0.039 \\
(0.012)\end{array}$ \\
\hline Intercepi & $\begin{array}{c}74.29 \\
(1.145)\end{array}$ & $\begin{array}{r}75.25 \\
(1.371\end{array}$ & $\begin{array}{c}9.162 \\
(0.325)\end{array}$ & $\begin{array}{c}9.57 ! \\
(0.388)\end{array}$ & $\begin{array}{c}6.206 \\
(0.957)\end{array}$ & $\begin{array}{c}6.662 \\
(0.990)\end{array}$ \\
\hline Adjusted $\mathbf{R}^{2}$ & .969 & .969 & .906 & .906 & .907 & .908 \\
\hline \multicolumn{7}{|c|}{ Models Using Fraction Eligible Under Targeted Expansions } \\
\hline $\begin{array}{l}\text { Fraction } \\
\text { Eligible }\end{array}$ & $\begin{array}{c}-7.749 \\
(4.123)\end{array}$ & $\begin{array}{c}-15.37 \\
(5.920)\end{array}$ & $\begin{array}{c}-1.752 \\
(1.176)\end{array}$ & $\begin{array}{c}-3.989 \\
(1.689)\end{array}$ & $\begin{array}{l}-1.439 \\
(1.170)\end{array}$ & $\begin{array}{l}-3.391 \\
(1.685)\end{array}$ \\
\hline Low Birtbweight & & & & & $\begin{array}{c}0.040 \\
(0.012)\end{array}$ & $\begin{array}{c}0.039 \\
(0.012)\end{array}$ \\
\hline Intercept & $\begin{array}{c}74.13 \\
(0.983)\end{array}$ & $\begin{array}{c}75.49 \\
(1.226)\end{array}$ & $\begin{array}{c}8.814 \\
(0.280)\end{array}$ & $\begin{array}{c}9.201 \\
(0.350)\end{array}$ & $\begin{array}{c}5.821 \\
(0.945)\end{array}$ & $\begin{array}{c}6.267 \\
(0.984)\end{array}$ \\
\hline Adjusted $\mathbf{R}^{\mathbf{3}}$ & .969 & .969 & .905 & .906 & .907 & .907 \\
\hline
\end{tabular}

Models Using Fraction Eligible Under Broed Expansions

\begin{tabular}{|c|c|c|c|c|c|c|}
\hline $\begin{array}{l}\text { Fraction } \\
\text { Eligible }\end{array}$ & $\begin{array}{l}-0.565 \\
(2.458)\end{array}$ & $\begin{array}{l}-1.451 \\
(6.178)\end{array}$ & $\begin{array}{c}-0.108 \\
(0.699)\end{array}$ & $\begin{array}{r}-0.336 \\
(1.757)\end{array}$ & $\begin{array}{c}-0.067 \\
(0.679)\end{array}$ & $\begin{array}{l}-0.232 \\
(1.706)\end{array}$ \\
\hline Low Birtbweight & & & & & $\begin{array}{c}0.072 \\
(0.023)\end{array}$ & $\begin{array}{c}0.072 \\
(0.023)\end{array}$ \\
\hline Intercept & $\begin{array}{c}74.35 \\
(1.406)\end{array}$ & $\begin{array}{c}74.35 \\
(1.397)\end{array}$ & $\begin{array}{c}8.440 \\
(0.400)\end{array}$ & $\begin{array}{c}8.447 \\
(0.397)\end{array}$ & $\begin{array}{c}3.081 \\
(1.743)\end{array}$ & $\begin{array}{c}3.089 \\
(1.742)\end{array}$ \\
\hline Adjusted $R^{2}$ & .981 & .981 & .910 & .910 & .916 & .916 \\
\hline
\end{tabular}




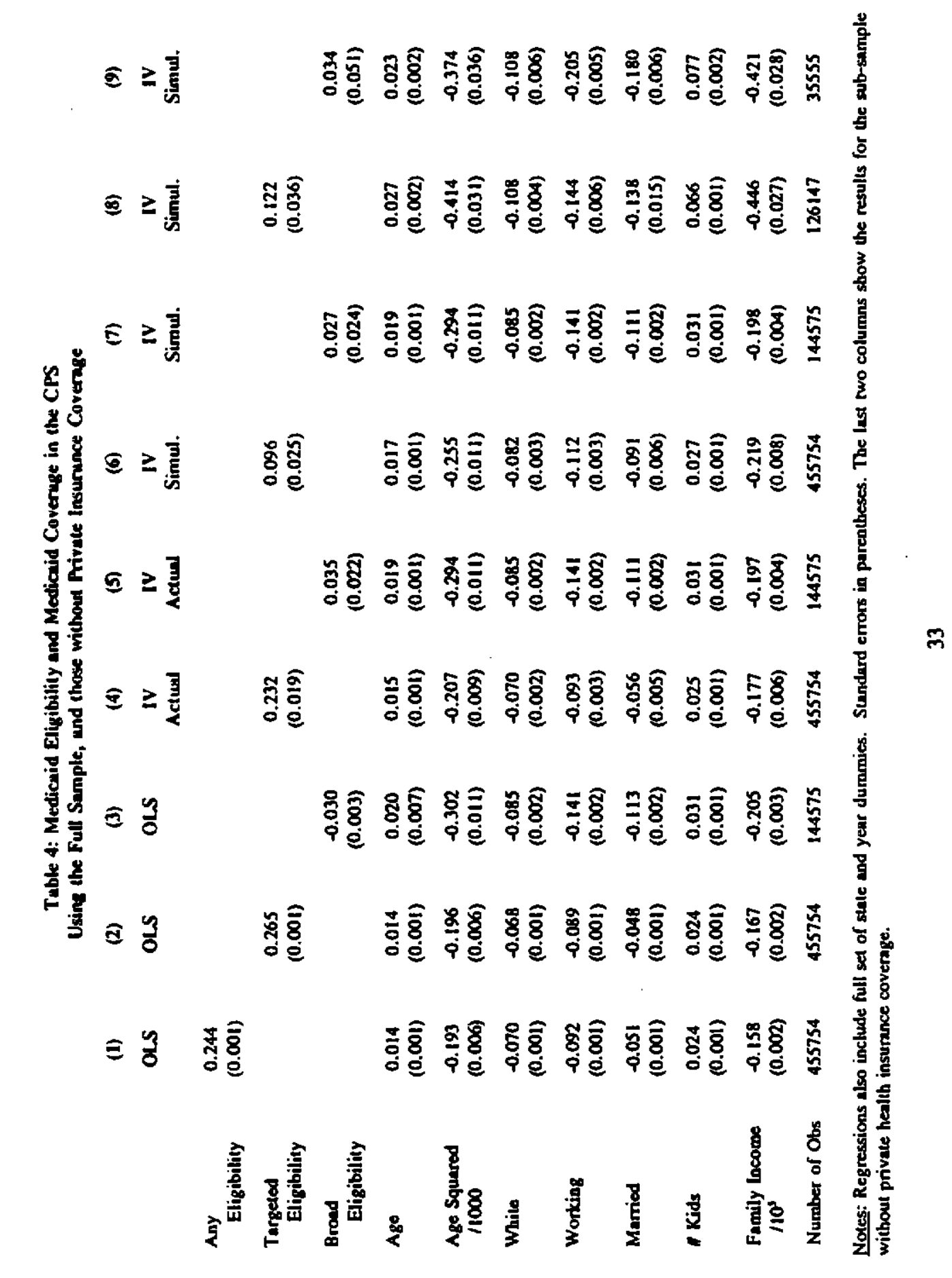


Tabie 5: Medicaid Eligibility and Medicaid Payments: Evidence from HCFA Data

Measure of Fraction Elig:

Overall Eligibility

Targeted Expansions
Actual

.206

(.077)

.357

$(.110)$

.137

(.154)
Simulated

Broad Expansions

.262

$(.187)$

Noles: This table shows the coefficient on various Medicaid eligibility variables from regressions including year and state dummies. For example, the coefficient under "actual" in the targeted expansions row refers to the coefficient on the actual fraction made eligible under the targeted expansions. Standard errors in parentheses. Dependent variable is payments in thousands of 1986 dollars per $15-44$ year old woman. 


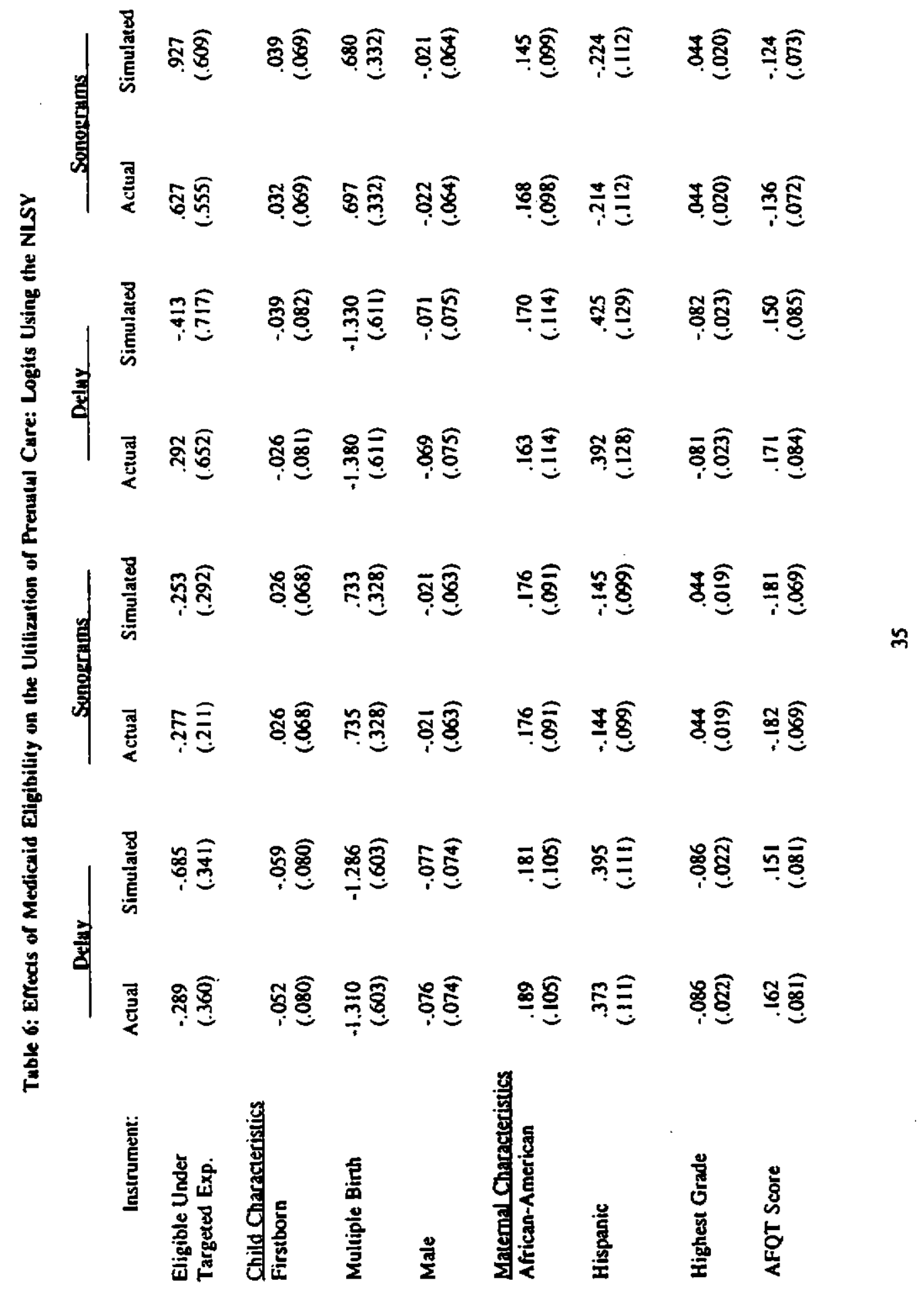




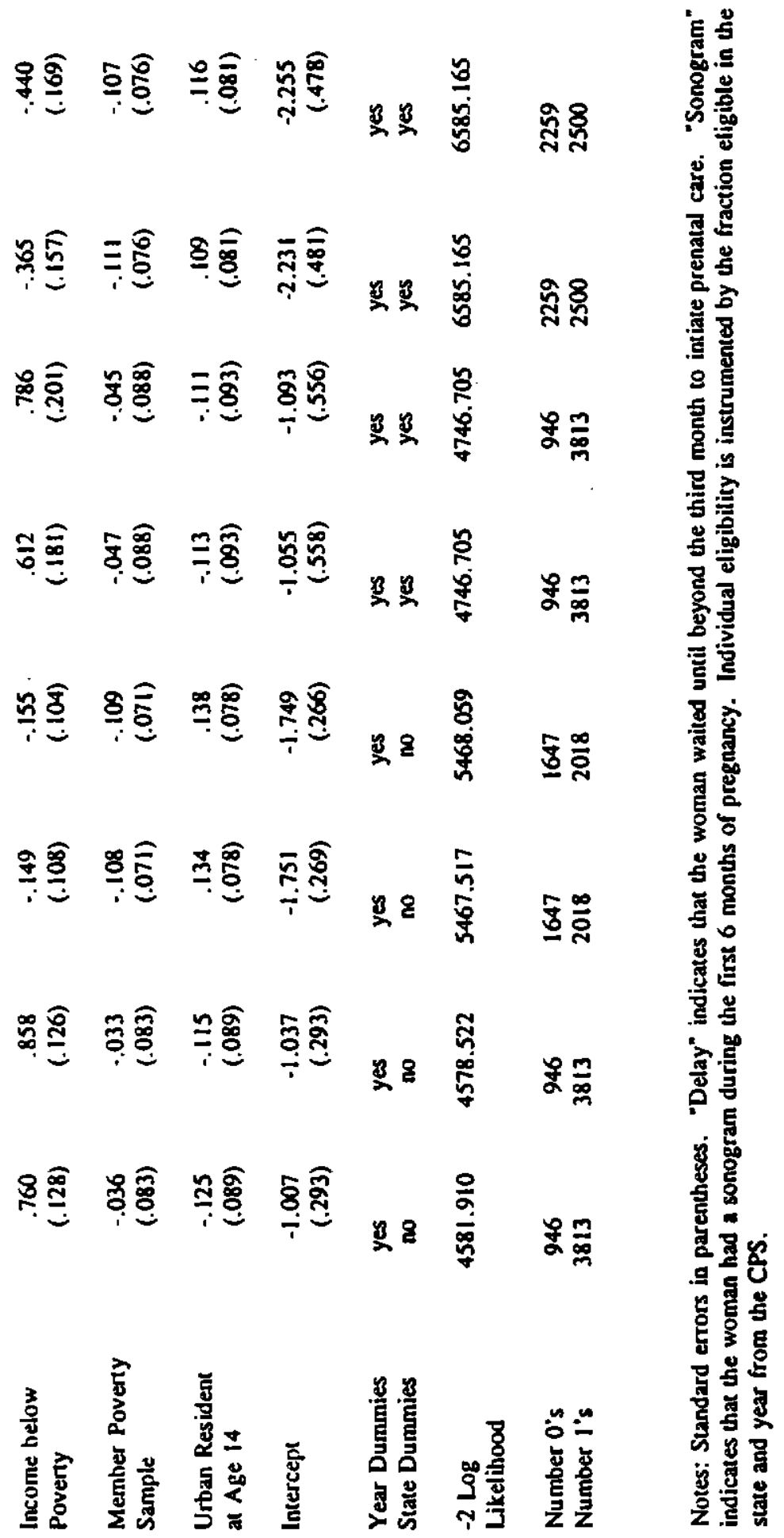



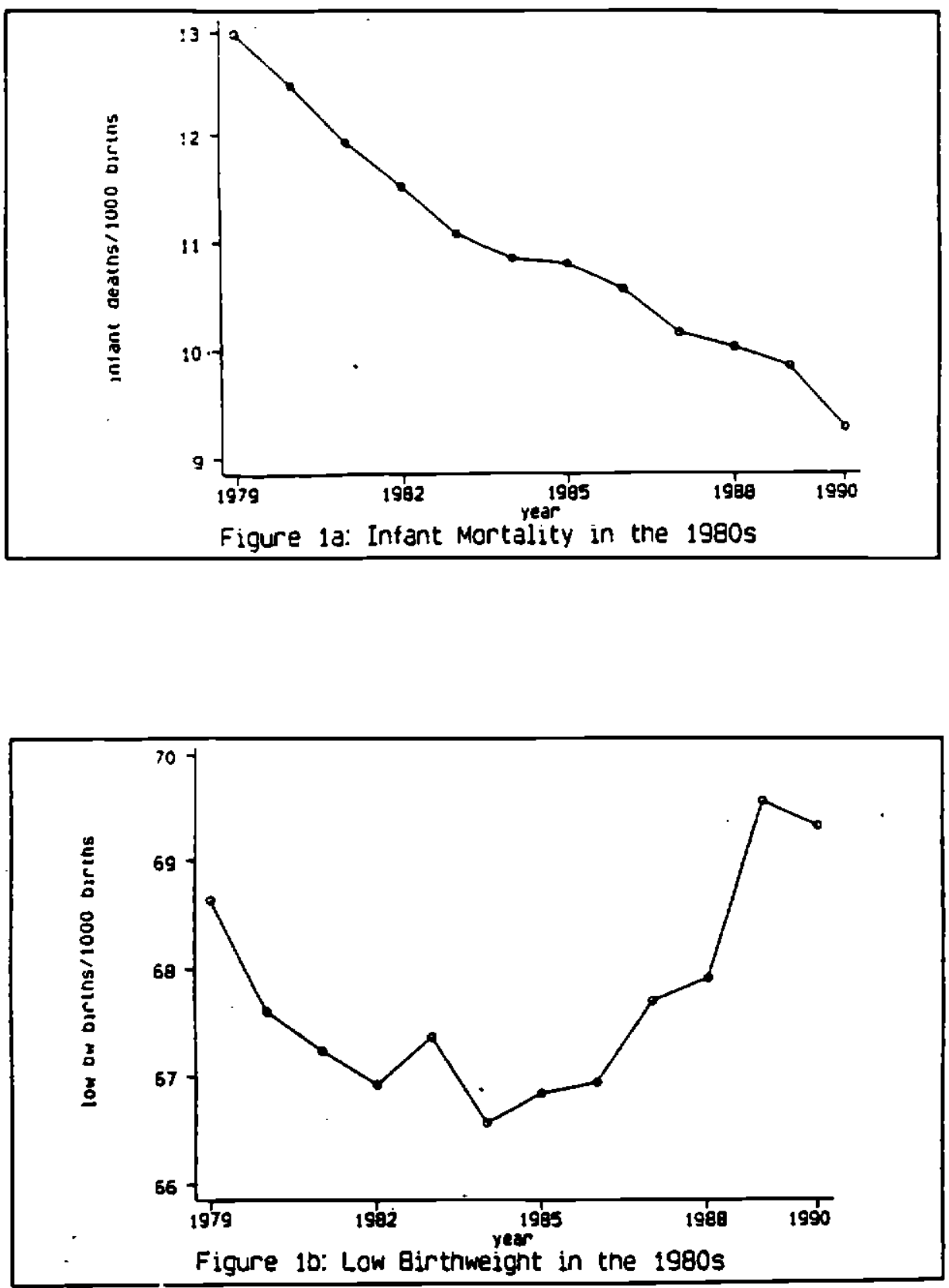

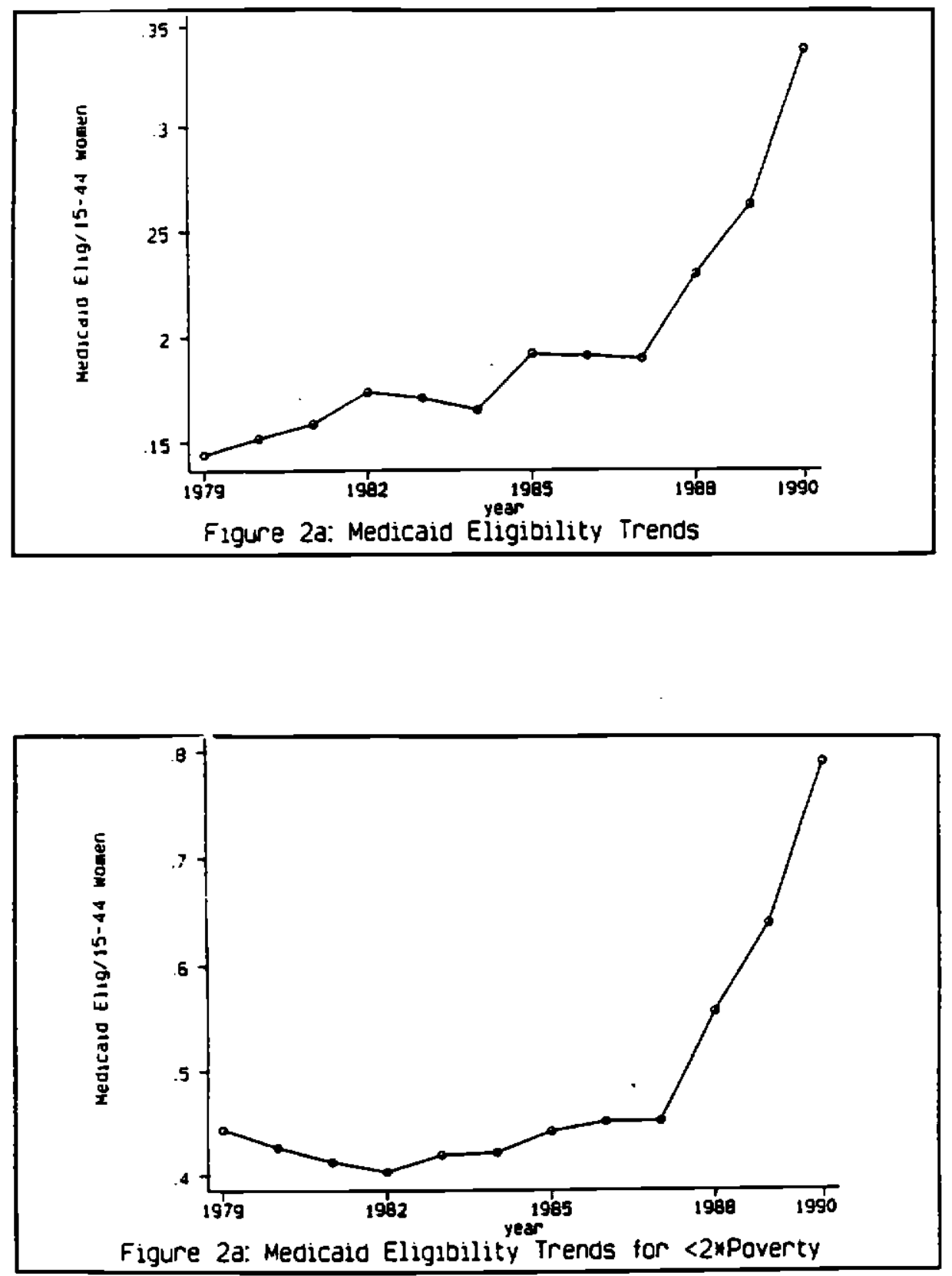

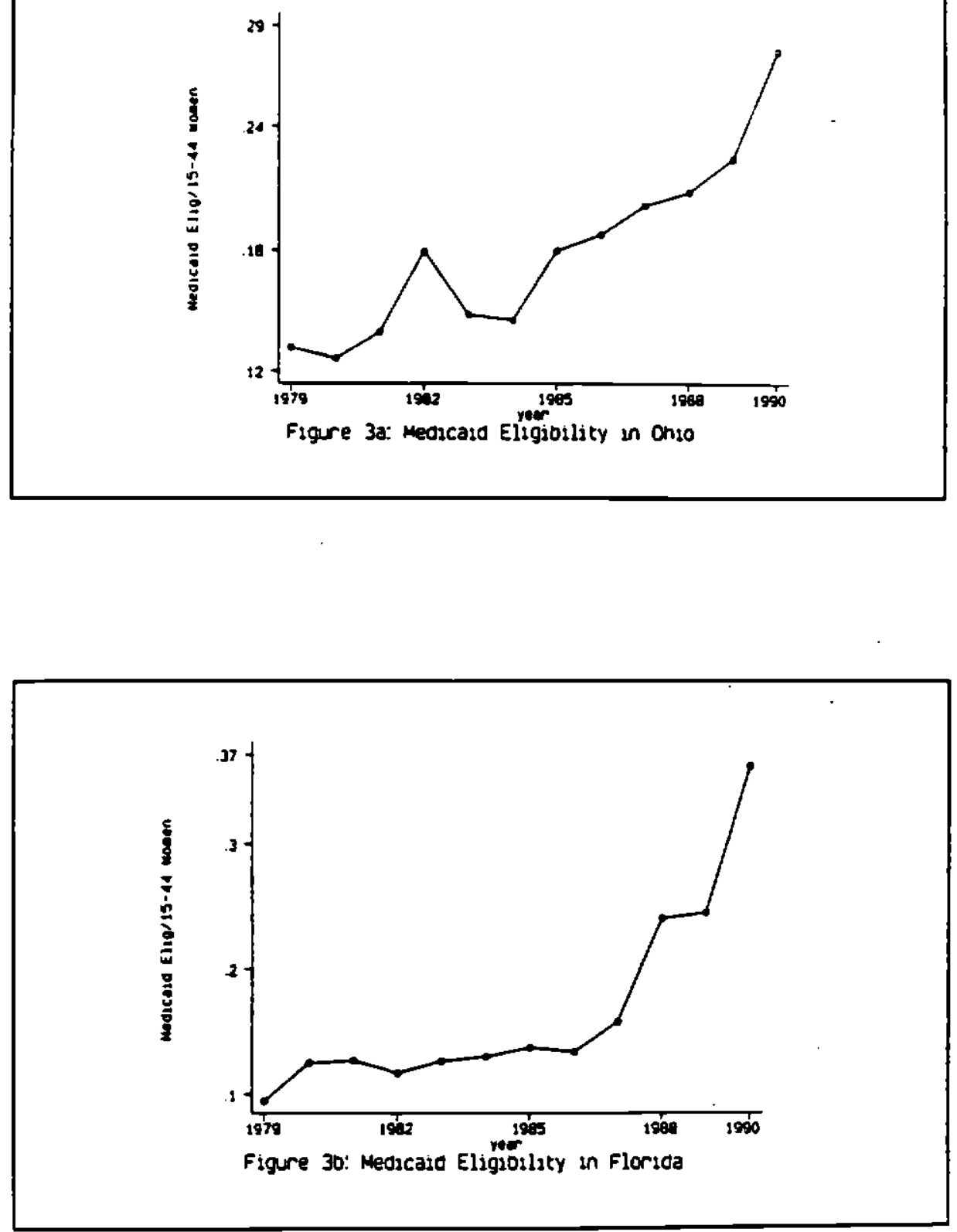


\section{References}

Alan Gutumacher Institute. The Financine of Maternity Care in the United States. New York: AGI, 1987.

American Public Welfare Association. "Voluntary Contributions and Provider-Specific Taxes: Survey Results". Washington, D.C.: APWA, 1991.

Buehler, J.W., J. Kleinman, and C. Hogue. "Birth Weight-Specific Infant Mortality, U.S., 1960 and 1980," Public Health Repors, 102 in, 1985, 3564-3567.

Buescher, et al. "An Evaluation of the Impact of Maternity Care Coordination on Medicaid Birth Outcomes in North Carolina," American Journal of Public Health, 81, 1991, 1625-1629.

Blank, Rebecca and David Card. "Recent Trends in Insured and Uninsured Unemployment: is There an Explanation?," Ouanterly Joumal of Econemics 106, November 1991, 1157-1190.

Blank, Rebecca and Patricia Ruggles. "When Do Women Use AFDC \& Food Stamps? The Dynamics of Eligibility vs. Participation," mimeo, July 1993.

Braveman, Paula, et al. "Adverse Outcomes and Lack of Health Insurance Among Newborns in an EightCounty Area of California, 1982 to 1986," The New England Joumal of Medicine, 321 \#8, August 24, 1989, 508-513.

Buehler, J.W., J. KJeinman, C. Hogue. "Birth Weight-Specific Infant Mortality, United Stares, 1960 and 1980," Public Health Repons 102 12, 1985, 3564-3567.

Chaikind, Stephen and Hope Corman. "The Special Education Costs of Low Birthweight," NBER Working Paper 13461, October 1990.

Children's Defense Fund. The Deficit Reduction Act of 1984. Washington, D.C.: Children's Defense Fund, 1984.

Creasy, R.K., B.A. Gummer, and G.C. Liggins, "System in Predicting Spontaneous Preterm Birch," Obsterrics and Gynecolory, 6, 1980, 692ff.

Corman, Hope, Theodore Joyce, and Michael Grossman. "Birth Outcome Production functions in the United States", Journal of Human Resources, 22, Summer 1987, 339-360.

Cropper, Maureen L., and Wallace E. Oates. "Environmental Economics: A Survey," Journal of Economic Likeranure, 30, June 1992, 675-740.

Cropper, Maureen L. et al.. "The Determinant of Pesticide Regulation: A Statistical Analysis of EPA Decision-Making," JournaL of Political Economy; 100, 1992, 175-197.

Currie, Janet and Nancy Cole. "Welfare and Child Health: The Link Between AFDC Participation and Birth Weight," The American Economic Review, 283 M. September 1993. 
Fischer, Michael. "Weighing the Evidence: An Empirical Analysis of the Expansions of Medicaid Coverage for Pregnant Women, 1984-1990". Thesis, Harvard College, 1992.

Frank, Richard, Donna Swrbino, David Salkever, Catherine Jackson. "Updated Estimates of the Impact of Prenatal Care on Birthweight Outcomes by Race," NBER Working Paper \#3624, February 1991.

Gold, Rachel, Susheela Singh and Jennifer Frost. "The Medicaid Eligibility Expansions for Pregnant Wornen: Evaluating the Strength of State Implementation Efforts", Eamily Plannine Perspectives, 25 is, September/October 1993, 196-207.

Government Accounting Office. Medicaid Expansions: Coverage Improves but State Fiscal Problems Jeopardize Continued Prosress. Washington, D.C.: GAO, June 1991.

Graham, John D., and James W. Vaupel. "Value of a Life: What Difference Does it Make?," Risk Analysis, $1 \mathrm{H1}, 1981,89-95$.

Grossman, Michael, and Steven Jacobowitz. "Variations In Infant Mortality Rates Among Countles of the United States: The Roles of Public Policies and Programs," Demorraphy, 18, Novernber 1981, 695-713.

Grossman, Michael and Theodore Joyce. "Unobservables, Pregnancy Resolutions and Birth Weight Production Functions in New York City," Lournal of Political Economy, 98 15, October 1990, 9831007.

Gruber, Jonathan. "The Effect of Price Shopping in Medical Markets: Hospital Responses to PPOs in California," forchcoming, lournal of Health Economics

Hanratty, Maria. "Canadian National Health Insurance and Infant Health". Mimeo, Cornell University, 1992.

Harris, Jeffrey. "Prenatal Medical Care and Infant Mortality," in Victor Fuchs, ed., Economic Aspects of Health, Chicago: University of Chicago Press, 1982.

Health Care Financing Administration. Analysis of State Medicaid Program Characteristics. Washington, D.C.: HCFA, 1982, 1983, 1984.

Health Insurance Association of America. The Cost of Maternity Care and Childbirth in the United States. 1989. Washington, D.C.: HLAA, 1990.

Hill, Ian. Medicaid Eligibility: A Descriptive Report of OBRA.TEERA and DEERA Provisions, and State Responses. Washington, D.C.: National Governors Association, 1985.

Hill, tan. Broadening Medicaid Coverage of Pregnant Women and Children: State Policy Responses. Washington, D.C.: National Governors Association, 1987.

Horbar, Jeffrey, Elizabeth Wright, Lynn Onstad et al., Decreasing Mortality Associated with the 
Introduction of Surfactant Therapy: An Observational Sudy of Neonates Weighing 601 to 1300 Grams at Birch," Pediatrics, 92 12. August 1993, 191-196.

Hutchens, Rober, George Jakubson, and Saul Schwartz (1989). "AFDC and the Formation of Subfarnilies," Joumal of Human Resources, 24, 1989, 599-628.

Instiutce of Medicine, Preventing Low Birthweight, Washington D.C.: National Academy Press, 1985.

Intergovernmental Health Policy Project. "Major Changes in State Medicaid and Indigent Care Programs". Eds. Debra J. Lipson et al. Washington, D.C.: The George Washington University, various years.

Manning, Williard G. et al. "The Taxes of Sin: Do Smokers and Drinkers Pay Their Way?," Journal of the American Medical Association, 261 "11, March 17, 1989, 1604-1609.

McCormick, Barbara, et al., "The Health and Developmental Status of Very-Low-Birthweight Children at School Age," Loumal of the American Medical Association, 267, 1992.

Meyer, Bruce. "A Quasi-Experimental Approach to the Effects of Unemployment Insurance," NBER Working Paper $\$ 3159,1989$.

Moffix, Robert. "Incentive Effects of the U.S. Welfare System: A Review," loumal of Economic Literature, 30, March 1992, 1-61.

Piper, J.M. ef al. "Effects of Medicaid Eligibility Expansion on Prenatal Care and Pregnancy Outcomes in Tennessee," Loumal of the American Medical Association, 264, 1990, 2219-2223.

Rosenzweig, Mark and T. Paul Schultz. "The Behavior of Mothers as Inputs to Child Health: The Determinants of Birth Weighe, Gestation, and Rate of Fetal Growth," in Economic Aspects of Health. Victor Fuchs (ed), University of Chicago Press: Chicago, 1982.

Rosenzweig, Mark and T. Paul Schultz. "Estimating a Household Production Function: Heterogeneity, the Demand for Health Inputs, and Their Effects on Birth Weight," loumal of Political Economy, 91 , October 1983, 723-746.

Rosenzweig, Mark and T. Paul Schultz. The Stability of Household Production Technology, A Replication," The Joumal of Human Resources, 23, Fall 1988, 535-549.

Rymer, Marilyn and Gerald Adler. "Children and Medicaid: The Experience in Four States," Health Care Financine Review, 9il, Fall 1987, 1-20.

Saywell, et al. "Hospital and Patient Characteristics of Uncompensated Hospital Care: Policy Implicarions." Loumal of Health Politics. Policy, and Law, 14, 1989, 287-307.

Schwartz, Rachel. "What Price Premanurity," Eamily Plannine Perspectives, 21, July/August 1989, 170174. 
U.S. Department of Health and Human Services (various years). Characteristies of Stare Plans for did 6 Families With Dependent Children. Washington, D.C.: US DHHS.

U.S. House of Representatives, Green Book 1992: Background Material on Programs Under the Jurisdiction of the Commirtee on Ways and Means, Washington D.C.: GPO, 1992

U.S. Office of Technology Assessment. Healthy Children: Investine in the Funure. OTA-H.34t. Washington, D.C.: GPO, 1987 .

U.S. Office of Technology Assessment. Neonatal Intensive Care for Low Birhweight Infants: Cosis and Effectiveness, OTA-HCS-38, Washingion, D.C.: GPO, $1987 \mathrm{~b}$.

Viscusi, Kip. Eatal Tradeoffs. New York: Oxford University Press, 1992.

Weitz, Judith. Testimony before House of Representatives on DEFRA (PL 98-369), 1983.

Yelowitz, Aaron. "The Medicaid Notch, Labor Supply and Welfare Participation: Evidence from Eligibility Expansions," MIT mimeo, July 1993.

Lurie, N. et al.. "Termination from Medi-Cal: Does it Affect Health?," New Englad Journal of Medicine, 311, 1984, 480-484. 


\section{Appendix: Eligibility Simulations}

During the entire period studied, 1979-90, the fundamental basis for eligibility for Medicaid was receipt of AFDC. The core of our eligibility calculation was therefore a simulation of eligibility for welfare receipt. In order to qualify for AFDC, a family must pass three tests: their gross income must be below a multiple of the state's needis standard (this test was applied from 1982 onwards only); ${ }^{33}$ their gross income less certain disregards for work expenses and child care must be below the state's needs standard; and their gross income less certain disregards less a portion of their earnings must be below the state's payment standard.

The exact definition of a family unit is the first source of difficulty in making this calculation. If a minor (which we define as less than age 19) is living with her parents, then a portion of the parents' income is deemed to that individual in making the eligibility calculation. This fraction is calculated by subtracting from family income the needs standard for a family of that size. If the individual is age 19 or above, then the treatunent of family resources is less clear, and varies across states; see Hutchens et al. (1989) for a description of these differing treatments. We assume, following the practice of the majority of the states, that the parent's resources are ignored if the individual is not a minor.

Before OBRA '81, there was no standardized allowance for work and child care expenses under AFDC. Beginning in October 1981, the allowance was standardized to be 575 per month for work expenses, and a maximum of $\$ 160$ per child for child care costs. This was not changed until the Family Support Act of 1988, which raised the altowances to $\$ 90$ for work expenses and $\$ 175$ per child for child care, effective October, 1989. For years before 1982, we assume that states allowed the same level of disregards as was designated under OBRA.

Before OBRA '81, there was a work incentive feature of AFDC known as " 30 and one-third". This incentive allowed families to keep the first $\$ 30$ of earned income, and one third of the remainder, while the other two-thirds led to reduced AFDC benefits. Since individuals must qualify for an AFDC payment in order to receive Medicaid, this meant that the individual's income, less disregards, and less $\$ 30$ and onethird, was compared to the payment standard for the third test described above. From 1982 to 1984, this incentive was limited to the first four months that individuals were on AFDC. In order to model this, we assume that for our sample it is their first full year on AFDC, so that they get $\$ 120$ and $1 / 9$ of their earnings for the year. From 1985 onwards, indlviduals who would have lost Medicaid due to the end of the $\$ 30$ and $1 / 3$ rule after 4 months were allowed to remain on Medicaid for an additional 9 to 15 months (the length was at state discretion). We modelled this as amounting to a full 30 and $1 / 3$ exclusion after 1984, parallel to the pre-1982 rules. Our object was to consistently model the maximum amount that an individual could have received under AFDC.

Finally, a key restriction on the receipt of AFDC is family structure. In all states, single women with at least one child are eligible. In addition, in some states, martied women with an unemployed spouse are eligible under the "AFDC-UP" progran. Eligibility for AFDC-UP conditions on both current employment status and work history. Lacking longitudinal data on work histories, we assume that fanilies are eligible if the state has a program and the spouse had worked less than 40 weeks in the previous year.

\footnotetext{
${ }^{31}$ From 1982 to 1984, this multiple was 1.5; from 1985 onwards, the multiple was 1.85 .
} 
Since families eligible for AFDC-UP make up only a small fraction of the overall AFDC population, this should not greatly affect our estimates

For most Medicaid recipients, AFDC receipt summarizes the necessary conditions for Medicaid eligibility. However, from the inception of the program, there have been a number of special options, to be used at state discretion, which allow furcher means of eligibility for certain populations, and, in particular, for pregnant women.

The first of these are state programs to cover single mothers who are pregnant for the first time, who are therefore not yet eligible for AFDC. Before 1982, a number of states had first-time pregnancy options under their AFDC programs, which covered women from some point in their pregnancy even if they had no other children. Generally, women were covered from the point of medical verification, although some states covered them at a later point; we only counted those states that covered women during the first trimester. In most states, the states counted only the mother in the family unit size (i.e. the size of the family was one), although a few states counted the future child as well. The states which had these programs are identified in U.S. Department of Health and Human Services (various years).

After OBRA ' 81 , states with these programs were no longer allowed to cover women before the sixth month of pregnancy. However, states were offered the option of deeming first-time pregnant women eligible for Medicaid from the moment of verification, even though AFDC payments had not yet begun to flow. As with most Medieaid-only options, information ibout which states took up this option is spoty and often contradictory. Based on information in Health Care Financing Administration $(1982,1983,1984)$, Weitz (1983), and Hill (1985, 1987), we came up wich a list of states which appeared to have taken up this option in each year. We also assumod that, under this program, states did not count the unborn child in determining the size of the assistance unit.

Under DEFRA '84, which was effective from 1985 onwards, states were required to cover 'a pregnant woman who would be elizible for Aid to Families with Dependent Children ... 2s if her child had been born and was living with her ..., (if) such pregnancy has been medically verified" (P.L. 98-369. Sec. 2361, Subtide 8). Thus, first-time pregnans women are covered in all states from 1985 onwards, and the effective family size for AFDC recelpt is increased by one for all pregnant women.

Another important state Medicaid option is coverage of "Ribicoff children", who are children who would qualify for AFDC under income considerations alone, but who would not qualify due to family structure (ie. children in poor two-parent families). Before 1981, states could cover selected categories of such children (ie. only those in institutions, only those in two-parent families, etc.), or all categories, up to age 21 . From 1982 onwards, they were also offered the option of restricting the coverage of children between 18 and 21 years of age. Thus, for ceens in our sample in states with comprehensive Ribicoff children programs, we ignored the tamily structure requirements of AFDC and only screened on income. ${ }^{34}$

\footnotetext{
${ }^{34}$ In theory, we should do this for any state whlch took up the Riblcoff option to cover poor children in two-parent families. However, the data on this program are spoty, and this category is never presented. Thus, we only included those states which were listed as having programs that covered all categories of Ribicoff children. The data on this program are from HCFA
} 
Furthermore, athough OBRA '81 restricted the AFDC coverage of unborn children, states were given the option of covering unborn children under their Ribicoff children programs. This amounted to covering pregnant women whose income qualified them for AFDC, regardless of family structure. We gathered information on this Riblcoff option from HCFA (1982,1983, 1984) and from Weitz (1983), and modelled it as being in place from 1982 onwards.

In addition, since the inception of the Medicaid program, states have had the option of covering all pregnant women whose income qualified them tor AFDC but who were not single mothers. This little known option is only discussed in Weitz (1983), Children's Defense Fund (1984), and Hill (1987); the last of these sources gives the dates of the inception of these programs.

Each of the three options Just listed (Ribicoff teens, Ribicoff unborn, and no family structure restrictions for pregnant women) apply only to the pregnant women herself, or only to her unborn child, so the family unit size (for example) for a first time pregnancy would be one. However, we assumed that when states had more than one of these programs, the fanily unit slze was lncreased by the fulure child.

The final state option of importance is the Medically Needy program, which is designed to cover individuals who meet the fanily structure requirements for AFDC and whose gross resources are above AFDC levels, but whose high medical expendiures bring their net resources below some certain minimal level. States who take up this option may establish Medically Needy thresholds that are no more than 133\% of the state's AFDC needs standard. Indlviduals can then "spend down" to these thresholds by subtracting their medical expenditures from their gross income; If they.do, Medicald will pay the remainder of their expenditures. 3

While this program may be quite useful for covering the birth expenditures of a pregnant woman whose Income is somewhat above the AFDC cutoff, it is unclear how important the Medically Needy opcion is for covering her prenstal care expenditures. We therefore model this program in two ways. First, we simply compare the women's net income to the Medleally Needy threshold; that is, this program will help to pay for the medical conts of women whose gross incomes are between the AFDC threshold and the Medieally Needy threshold. Second, we suberect from eross income the expected global fee for an obstetriclan, from Alan Gutumacher Instiante (1987). ${ }^{*}$ The notion here bs that, if obatetricians bill the pregnane mother for their globel teo at the firs prenatal care visit, then the mocher will be able to use this bill to qualify for the Medically Needy progrem. Since the measures were very similar, we only used the former in the enalysis.

Beginning with DEFRA '84, the Federal governmem began a series of mandates which extended

$(1982,1983,1984)$ and Hill $(1987)$.

15 The time frame over which such spend-down occurs varies across the states, and we do not model it.

"The global fee is the bill for all obstetric services, including pre-natal care, delivery, and postnatal care. This fee averaged $\$ 830$ in 1986, and is deflated (and infated) to other years using the physician's services component of the Consumer Price Index. 
the Medicaid coverage of pregnant women. DEFRA '84 included two features: mandatory coverage of pregnant women under AFDC (described above), and mandatory coverage of pregnant women in AFDC. UP type families, even if the state did not have an AFDC-UP program. COBRA 85 then mandated that pregnant women who met the AFDC resource standards were eligible regardless of family structure (similar to the state programs described above). This law was effective in July, 1986. Since we are focusing primarily on the effect of Medicaid on early prenatal care, we model this law as being effective from 1987 onwards.

Beginning with OBRA '86, states were first given the option, and then mandated to, increase the income thresholds for Medicaid eligibility, regardless of family structure. OBRA '86 gave states the option of covering pregnant women up to $100 \%$ of the poverty threshold, beginning in April, 1987. OBRA ' 87 increased that optional level to $185 \%$ of poverty. Under the Medicare Catastrophic Care Act states were mandated to cover pregnant women up to $75 \%$ of poverty by July 1 . Then under OBRA ' 89 , they were required to cover women up to $133 \%$ of poverty by April, 1990 . Using data from Covernment Accounting Office (1991), Fischer (1992), and Intergovernmental Health Policy Project (various years), we modelled women as being covered if their income was below the average percentage of poverty that was covered during the year. 